\title{
Characterization of blisters on powder coated aluminium AA5006 architectural profiles
}

\author{
Zaffaroni, Giorgio Giovanni Battista; Gudla, Visweswara Chakravarthy; Ud Din, Rameez; Ambat, Rajan
}

Published in:

Engineering Failure Analysis

Link to article, DOI:

10.1016/j.engfailanal.2019.04.039

Publication date:

2019

Document Version

Peer reviewed version

Link back to DTU Orbit

Citation (APA):

Zaffaroni, G. G. B., Gudla, V. C., Ud Din, R., \& Ambat, R. (2019). Characterization of blisters on powder coated aluminium AA5006 architectural profiles. Engineering Failure Analysis, 103, 347-360.

https://doi.org/10.1016/j.engfailanal.2019.04.039

\section{General rights}

Copyright and moral rights for the publications made accessible in the public portal are retained by the authors and/or other copyright owners and it is a condition of accessing publications that users recognise and abide by the legal requirements associated with these rights.

- Users may download and print one copy of any publication from the public portal for the purpose of private study or research.

- You may not further distribute the material or use it for any profit-making activity or commercial gain

- You may freely distribute the URL identifying the publication in the public portal 


\section{Accepted Manuscript}

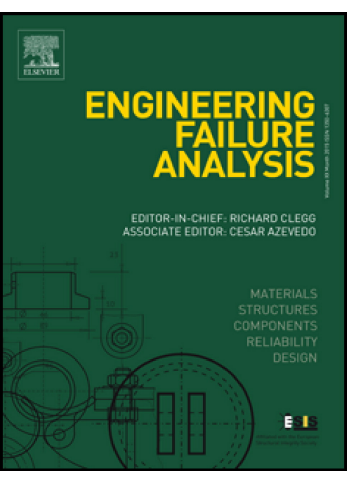

Characterization of blisters on powder coated aluminium AA5006 architectural profiles

Giorgio Giovanni Battista Zaffaroni, Visweswara Chakravarthy Gudla, Rameez Ud Din, Rajan Ambat

PII:

S1350-6307(18)31319-0

DOI: https://doi.org/10.1016/j.engfailanal.2019.04.039

Reference: EFA 3892

To appear in: Engineering Failure Analysis

Received date: 17 October 2018

Revised date: 3 April 2019

Accepted date: 24 April 2019

Please cite this article as: G.G.B. Zaffaroni, V.C. Gudla, R. Ud Din, et al., Characterization of blisters on powder coated aluminium AA5006 architectural profiles, Engineering Failure Analysis, https://doi.org/10.1016/j.engfailanal.2019.04.039

This is a PDF file of an unedited manuscript that has been accepted for publication. As a service to our customers we are providing this early version of the manuscript. The manuscript will undergo copyediting, typesetting, and review of the resulting proof before it is published in its final form. Please note that during the production process errors may be discovered which could affect the content, and all legal disclaimers that apply to the journal pertain. 


\title{
Characterization of blisters on powder coated aluminium AA5006 architectural profiles
}

Giorgio Giovanni Battista Zaffaroni ${ }^{a}{ }^{*}$, Visweswara Chakravarthy Gudla ${ }^{b}$, Rameez Ud Din ${ }^{c}$,

$$
\text { Rajan Ambat }{ }^{d}
$$

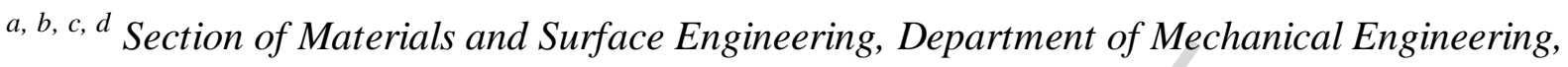
Technical University of Denmark, Produktionstorvet, Kongens Lyngby, 2800 Denmark

*Corresponding author: giogbz@mek.dtu.dk

\begin{abstract}
Investigation of premature blistering and delamination of coated AA5006 window frames using scanning (SEM) and transmission electron microscopy (TEM), glow discharge optical emission spectroscopy and X-ray photoelectron spectroscopy (XPS) is presented. SEM of the blisters revealed corrosion of Aluminium and accumulation of corrosion products at the interface of coating and metal. TEM and XPS analysis revealed a thin and non-homogenous hexavalent $\mathrm{Cr}$ conversion layer. High number density of intermetallics, and surface defects from metal forming process resulted in a defective conversion coating leading to reduced corrosion protection of aluminium in the presence of water and $\mathrm{Cl}$ from atmosphere.
\end{abstract}

Keywords: Aluminum; Intermetallics; Interface analysis; Blistering; Corrosion.

Declarations of interest: none.

This research did not receive any specific grant from funding agencies in the public, commercial, or not-for-profit sectors. 


\section{Introduction}

Aluminium alloys are widely used in aerospace, automotive, construction, consumer electronics, marine, and food packaging industries [1][2]. The wide area of applications for $\mathrm{Al}$ arises from its favourable strength to weight ratio, ease of formability, economic recyclability, inherent passivating and corrosion resistant nature, along with the ability to be surface engineered and treated to suit various functional application needs [3][4]. Aluminium alloys are generally passive in $\mathrm{pH}$ domain from $3-8$, however in aggressive conditions corrosion degradation occurs due to localised pitting, intergranular corrosion (IGC) attack, and stress corrosion cracking (SCC) [5]. In order to combat this, the $\mathrm{Al}$ components are generally surface pre-treated by caustic etching or mild degreasing, conversion coated using techniques based on chemical or electrochemical methods and then applied with an organic primer and/or a top coat [6][7]. However, recent increase in the complexity of $\mathrm{Al}$ alloy chemistries, use of recycled $\mathrm{Al}$ alloys, and conversion coating technologies other than those based on the conventional $\mathrm{Cr}(\mathrm{VI})$ based processes, in order to satisfy environmental regulations, has given rise to new challenges in corrosion control of Al alloys [8][9].

Degradation of pre-treated, conversion coated and painted Al alloys occurs generally due to water ingress and presence of corrosive species such as $\mathrm{Cl}$. This causes degradation and failure by filiform corrosion and blistering followed by delamination of the paint [10][11][12]. Generally, the primer and topcoat system are optimized to provide the best barrier properties to prevent water and corrosive species ingress to the underlying metal surface. However, once water and corrosive species penetrate the paint layer, factors such as the alloy microstructure, composition, local changes in morphology at the surface and the quality of pre-treatment or conversion layer play a crucial role in determining the electrochemical nature and corrosion resistance of the $\mathrm{Al}$ alloy. Recycling of $\mathrm{Al}$ alloys generates a microstructure with a higher degree of heterogeneity caused by an increase in intermetallic phase particles and trace elements which alter the electrochemical 
nature of the alloy [13]. This results in degradation of inherent corrosion resistance of the recycled alloys compared to those of primary alloys, as well as decrease in the quality of pre-treatments and subsequent conversion coatings applied to these Al surfaces [14]. Further, local variations in the structure and composition of the $\mathrm{Al}$ surface, compared to that of the alloy bulk, also pose additional challenges for corrosion control. Several authors have emphasized on the variation in electrochemical nature at the surface of commercial $\mathrm{Al}$ alloys, compared to that of the bulk, due to presence of local heterogeneity at the top surface induced by prior thermal and/or mechanical processing. The presence of a highly deformed surface region (also known as near surface deformed layers; altered surface layers; Beilby layer) was identified as the underlying reason for the observed accelerated corrosion degradation of painted Aluminium surfaces [15][16][17].

In this work, we present an investigation of rolled Aluminium AA5006 window frame profiles that displayed premature failure due to blistering of the applied powder coating. The material was analysed for the microstructure, and the blistered regions were characterized for their composition, sub-surface structure and morphology, using scanning electron microscopy (SEM) and focused ion beam microscopy (FIB-SEM). Transmission electron microscopy (TEM) was employed to understand the local structure of the Al metal-conversion coating-powder coating interface. Depth profiling for elemental distribution in the coating and the interface was performed using glow discharge optical emission spectroscopy (RF-GDOES) and the nature of the interface was investigated using X-ray photoelectron spectroscopy (XPS). The obtained results are correlated and the mechanism behind the blistering of the coated $\mathrm{Al}$ profiles is inferred.

\section{Experimental}

\subsection{Material}


A series of coupons $(1 \mathrm{~cm} \times 1.5 \mathrm{~cm})$ were prepared by cutting coated window frame profile. The Al alloy used was EN AW 5006 H49 grade. The coated profiles displayed surface blistering and premature coating delamination. Aluminium sheets of the same material and manufacturing history, without any surface pre-treatment and coating, were obtained for reference analysis. The chemical composition of the received reference $\mathrm{Al}$ alloy is presented in Table 1 .

\subsection{Visual appearance}

The preliminary examination of the coated $\mathrm{Al}$ profiles was carried out with unaided visual inspection, followed by general digital photography of the entire part and the blistered regions. A schematic representation, showing the cross-section of window frame profiles, is presented in Figure 1.

\subsection{Sample preparation}

Investigation of the surface below the blisters in the coating was performed by surgically cutting the coating around the blistered region, followed by mechanically peeling off the blistered coating using a pair of sterilized stainless steel tweezers. This exposed the underlying Al metal substrate, and the contents in the blister. Additionally, for characterizing the cross sections of the samples, the coupons prepared from the blistered regions, as well as from the reference $\mathrm{Al}$ sheet material, were vertically oriented, mounted in a Struers SpeciFix-20 $20^{\mathrm{TM}}$ epoxy and room temperature cured. The moulded samples were then subjected to mechanical grinding using silicon carbide polishing papers, subsequently from 220 grit to 4000 grit, with intermediate alcohol rinsing between each step. Fine polishing of the surfaces was performed using a $3 \mu \mathrm{m}, 1 \mu \mathrm{m}$, and a $1 / 4 \mu \mathrm{m}$ diamond suspension with intermediate rinsing, and finally followed by warm air drying. The entire mechanical polishing was carried out using ethanol $(99.99 \%$ purity) as a lubricant in order to prevent any dissolution and loss of corrosion products by water based preparation methods. 


\subsection{Microstructural characterization}

Scanning electron microscopy was employed to characterise the coated, blistered, as well as reference AA5006 profiles. Energy-dispersive X-ray spectroscopy was performed for obtaining the elemental analysis from the regions of interest. A scanning electron microscope model FEI Quanta 200 ${ }^{\mathrm{TM}}$ ESEM FEG equipped with an energy dispersive spectrometer (EDS) (Oxford Instruments 80 $\mathrm{mm}^{2}$ X-Max ${ }^{\mathrm{TM}}$ coupled with an Aztec ${ }^{\mathrm{TM}}$ SEM-EDS software) was used for the analysis. In-situ sectioning and imaging of the regions of interest was performed using a FEI Helios Nanolab ${ }^{\text {TM }}$ Dual beam FIB-SEM. Transmission electron microscopy was performed on the samples prepared from the regions of interest using a FEI Tecnai ${ }^{\mathrm{TM}} \mathrm{T} 20 \mathrm{G}^{2}$ operating at $200 \mathrm{keV}$. EDS analysis and mapping was performed in the TEM using scanning TEM mode and data were collected using an Oxford Instruments $80 \mathrm{~mm}^{2} \mathrm{X}-\mathrm{Max}^{\mathrm{TM}}$ detector coupled to a Aztec ${ }^{\mathrm{TM}}$ TEM-EDS analysis software. Thin film lamella from the region of interest for the TEM analysis were prepared using site specific in-situ lift out technique using FIB milling, and the in-situ lift out of the thin film lamella was performed using an Omniprobe ${ }^{\mathrm{TM}}$ micromanipulator coupled to the FIB-SEM [18][19][20][21]. The thin film samples that were lift out were further thinned down to approx. $100 \mathrm{~nm}$ thickness for electron transparency and were milled with a low energy $\mathrm{Ga}$ ion beam $(1 \mathrm{keV})$ to remove any prior high-energy milling induced artefacts. Mounting of the thin film lamella was performed onto Mo TEM sample grids with the help of in-situ Pt deposition to weld the sample to the grid.

\section{$2.5 \quad$ RF-GDOES}

Radio frequency glow discharge optical emission spectroscopy (GD-Profiler 2, Horiba Jobin Yvon) was employed to analyse the distribution of elements as a function of depth on the coated $\mathrm{Al}$ profiles. The applied sputter power was $40 \mathrm{~W}$ and the Ar pressure in the sputtering chamber was $800 \mathrm{~Pa}$. The diameter of the sputter crater was $4 \mathrm{~mm}$ with a total sputtering time of $1200 \mathrm{~s}$. The 
instrument was coupled with a software package (Quantum XPTM) for analysing and quantifying the data.

\subsection{X-Ray Photoelectron Spectroscopy}

XPS analysis was performed on the reverse of the window profile coupons where there was no powder coating applied (see Figure 1). This enabled to characterize a conversion coating pretreatment (if any) on the AA54006 profiles prior to powder coating application. Characterization was performed using a Thermo Scientific K-Alpha X-ray photoelectron spectrometer equipped with an $\mathrm{Al} \mathrm{K \alpha}(1486.6 \mathrm{eV}) \mathrm{X}$-ray source. Spectra were recorded in vacuum of approximately $2 \times 10^{-8}$ mbar. Ar sputtering was performed on the surface using an $\mathrm{Ar}$ ion gun operating at $2 \mathrm{keV}$ accelerating voltage for $60 \mathrm{~s}$, in order to remove the adsorbed species and surface contamination from the foam on the metal specimens. The high-resolution spectra were acquired with a pass energy of $50 \mathrm{eV}$; and 5 scans were performed in each case with a dwell time of $50 \mathrm{~ms}$. Shirley-type background removal, deconvolution and peak fitting (symmetrical Gaussian-Lorentzian) of the recorded spectra were performed using a Thermo Avantage ${ }^{\mathrm{TM}}$ software.

\section{Results}

\subsection{Visual appearance of the AA5006 profiles}

Figure 2 shows a representative image of the powder coated AA5006 profile where the presence of blisters of approx. 1-4 mm in diameter were observed. Majority of these blisters were concentrated at the edge of the Aluminium profile that was in contact with a rubber/polymer based material, which is used as a gasket for sealing purposes. 


\subsection{Surface morphology and microstructure of AA5006}

The back scattered electron images of the surface of the uncoated AA5006 reference sheets is shown in Figure 3. The analysis revealed the presence of streaks and shingle defects on the surface of the $\mathrm{Al}$ which are a characteristic of the thermomechanical processing step [22]. Intermetallic phase particles in high number density of various sizes (which appear bright in the back scattered SEM images due to atomic number contrast) are observed, and are found to be localised and agglomerated around the streak and shingle defects, as seen in Figure 3(b). The EDS analysis (not shown here) of the bigger (constituent) intermetallic phase particles showed that they are $\mathrm{Al}-\mathrm{Fe}$ Mn-Si type. The cross section of the AA5006 profile shown in Figure 4 highlights the high number density of the intermetallic phase particles that are aligned in the rolling direction, and the surface defects that extend to a considerable depth below the surface of the AA5006.

\subsection{Surface analysis of blistered profiles}

The secondary electron topography image of the blisters on the powder coated AA5006 profile (Figure 5) show that there are no observable cracks or porosity on the surface of the blisters. The EDS analysis (not shown here) of the blisters showed presence of Chlorine along with Fluorine and Sulphur.

In order to better understand the composition, structure, and morphology of the regions below the blisters, the surface below the blistered area was revealed by surgically removing the powder coating on the top of the blister and the secondary electron image providing an overview of the same is presented in Figure 6(a). EDS analysis of the contents in the blistered region revealed presence of $\mathrm{Al}$ and $\mathrm{O}$, suggesting corrosion of the $\mathrm{Al}$ substrate and accumulation of the corrosion products under the powder coating. Figure 6(b) shows the back scattered electron image at a higher magnification from the blistered region, after removal of the top powder coating, showing that the 
corrosion product is accumulated over the AA5006 profile and displays a mud crack morphology. The initiation, and the actual site of corrosion is however not visible and is assumed to be masked by the corrosion products.

The preferential propagation of corrosion along the surface streak defects (as seen in Figure 3) on the AA5006 profile is seen in Figure 7. The defects associated with bright appearing intermetallic phases that are agglomerated and oriented along the extrusion/rolling direction appear to be the preferential direction for lateral corrosion propagation, an instance of which is evident from the Figure 7(b). In addition, the surface of the AA5006 subject to corrosion degradation can be observed at the lower right corner of the image in Figure 7(b) and is characterised by dimple-like or scalloped morphology, which is typical of dissolution of Al [23]. The EDS analysis performed on the corrosion product, and the exposed $\mathrm{Al}$ surface (presented in Table 2) reveals presence of $\mathrm{Cr}$ on the exposed $\mathrm{Al}$ surface, and $\mathrm{Al}, \mathrm{O}$, and $\mathrm{Cl}$ in the corrosion product.

\subsection{Cross-section analysis of powder coated profiles}

The cross-section of the coated AA5006 profiles is shown in Figure 8, where the AA5006 substrate, the primer with the fillers and the top coat are visible. The thickness of the coating on the Al profiles is approx. $20 \mu \mathrm{m}$, and the interface of the metal with the primer is characterized by a high degree of roughness, which can be attributed to the observed surface roughness on the AA5006 reference sheet in Figure 4. The EDS analysis from the primer region presented in Table 2 shows presence of $\mathrm{Cr}, \mathrm{Ti}, \mathrm{Cu}, \mathrm{Si}, \mathrm{O}$, and $\mathrm{Fe}$.

The cross sections, prepared from the blistered regions on the coated profiles, are shown in Figure 9. Three distinct regions are identified from the backscattered electron images, namely, the top coating layer, the corrosion product below the coating that is contained in the blistered region and the AA5006 substrate that also displays some amount of corrosion degradation. In addition, the progression of the corrosion in the substrate material is in a lateral direction following the direction 
of the thermomechanical process (see Figure 10(a)) similar to that observed in Figure 7(b). Higher magnification images in Figure 10(b) show that the corrosion attack observed in the AA5006 profile is in close resemblance to that of pitting and intergranular corrosion (IGC) [24][25].

\subsection{Transmission electron microscopy}

The interface of the coating (primer or base coat) and the AA5006 substrate was prepared and observed in-situ in the scanning electron microscope using focused ion beam milling. Figure 11 highlights the presence of a 'shingle defect' at the interface of the powder coating with the metal. This region was further processed using focused ion beam in-situ lift out technique to prepare a thin film lamella for transmission electron microscopy.

Figure 12(a) shows the bright field transmission electron micrograph obtained from the interface region of the AA5006 profile with the applied coating. The surface of the $\mathrm{Al}$ profile is characterized by a deformed layer, which is observed as elongated grains parallel to the rolling direction, with a maximum grain size width of $500 \mathrm{~nm}$. In addition, intermetallic phase particles are observed within the bulk of the $\mathrm{Al}$ substrate as well at the surface. The applied coating displays fillers distributed in a carbon based matrix. The interface of the $\mathrm{Al}$ profile with the applied coating is characterized by a thin mushy appearing layer evident in Figure 12(a), suggesting an additional interfacial layer. The presence of an intermetallic particle at the 'shingle defect' on the surface of the AA5006 is confirmed from Figure 12(b). There is a higher degree of heterogeneity in the proximity of the defect in terms of morphology of the interfacial layer. In order to characterize the composition of this interfacial layer, EDS elemental mapping was performed using scanning transmission electron microscopy mode on this region, which is presented in Figure 13.

The EDS elemental maps in Figure 13 show that the interfacial layer between the Al profile and the coating is enriched in $\mathrm{Cr}$, O, and $\mathrm{Si}$ (approx. $120 \mathrm{~nm}$ thick). In addition, Figure 12 and the $\mathrm{Cr}$, and O EDS elemental maps in Figure 13, show a certain degree of heterogeneity in the thickness 
and the porosity of this enriched layer near the intermetallic phase particle (shingle defect). The intermetallic particles are mainly composed of $\mathrm{Fe}, \mathrm{Mn}$, and $\mathrm{Si}$ along with $\mathrm{Al}$, whereas the fillers in the coating are composed of $\mathrm{Fe}, \mathrm{Mn}, \mathrm{Cr}$, $\mathrm{Ti}$, and $\mathrm{O}$. The individual composition of these different observed features is listed in Table 3 .

\subsection{RF-GDOES Depth Profiling}

The elemental distribution, as a function of sputtering time, from the surface of the coated sample, obtained using radio frequency glow discharge optical emission spectroscopy, is presented in Figure 14. The sputter profiles are in accordance with the observed elemental maps from the STEM EDS analysis. The region corresponding to the top coat is demarcated to a sputtering time of 250 s during which presence of $\mathrm{C}, \mathrm{O}$, and $\mathrm{H}$ is visible. $\mathrm{Fe}, \mathrm{Cu}, \mathrm{Ti}$, and $\mathrm{Cr}$ along with $\mathrm{H}$, and $\mathrm{O}$ in the primer region or base coat can be clearly observed in the region following the top coat after $250 \mathrm{~s}$ of sputtering. The peaks from the filler elements in the primer are followed by a second plateau from $\mathrm{Cr}$, and $\mathrm{O}$ at approx. $500 \mathrm{~s}$ of sputtering time corresponding to the enriched $\mathrm{Cr}$ based interfacial layer. This region is further followed by an increasing signal from $\mathrm{Al}$, and $\mathrm{Mg}$ that saturates after $900 \mathrm{~s}$ of sputtering, indicating the bulk of the AA5006 alloy.

\subsection{X-Ray Photoelectron Spectroscopy}

The XPS analysis performed on the reverse side of the coated AA5006 profiles is presented in Figure 15 and Figure 16. The analysed surface had not been coated and was exposed by carefully flattening out the folded $\mathrm{Al}$ profile to characterize the $\mathrm{Al}$ surface for the presence of a pre-treatment or conversion coating if any. Survey scan shown in Figure 15, reveals presence of $\mathrm{Cr}, \mathrm{O}, \mathrm{Na}, \mathrm{Si}, \mathrm{Al}$, $\mathrm{Mg}, \mathrm{C}$, and $\mathrm{F}$ as the major identifiable elements.

The high-resolution spectra obtained for $\mathrm{Al} 2 p, \mathrm{Cr} 2 p, \mathrm{Si} 2 p$, and $\mathrm{O} 1 s$ are presented in Figure 16. Deconvolution of the observed peaks and peak fitting using data in literature reveal 
presence of $\mathrm{Al}$, oxides of $\mathrm{Al}$ and $\mathrm{Si}$, along with oxides and hydroxides of $\mathrm{Cr}$ on the surface of AA5006 alloy [26][27]. The peak binding energies after peak fitting for $\mathrm{Cr} 2 p_{3 / 2}$ singlet show that $\mathrm{Cr}$ exists in the form of $\mathrm{Cr}(\mathrm{III}), \mathrm{Cr}(\mathrm{IV})$, and $\mathrm{Cr}(\mathrm{VI})$ on the surface. The relative area percentage, for each of the different identified $\mathrm{Cr}$ species, is presented in Table 4. High resolution $\mathrm{O} 1 s$ spectrum reveals presence of Oxygen bound as metal oxides, hydroxyl groups mainly from $\mathrm{Cr}(\mathrm{OH})_{3}$ and as organic $\mathrm{C}=\mathrm{O}$ (overlaps with $\mathrm{H}_{2} \mathrm{O}$ ). The remaining part is assumed to arise from the carbon based polymer foam that is placed in the AA5006 profile to provide thermal and acoustic insulation.

\section{Discussion}

Characterization of the reference AA5006 sheet material showed a high number density of intermetallic particles based on Al-Fe-Mn-Si, as measured using EDS. In addition, severe streaking and shingling of the rolled $\mathrm{Al}$ surface is observed, which is also associated with intermetallic phases agglomeration. SEM and EDS analysis of the blistered regions on the AA5006 profiles showed that the blisters contain corrosion products or oxides of $\mathrm{Al}$ and traces of $\mathrm{Cl}$ were observed. Corrosion propagation was along the rolling direction in the regions of higher number density of intermetallic phases and the corrosion attack into the substrate closely resembled IGC type attack. The applied coating on the AA5006 profile showed presence of a primer/base coat and a top coat with a total thickness of approx. $20 \mu \mathrm{m}$. The base coat/primer showed presence of various kinds of fillers based on $\mathrm{Cr}, \mathrm{Fe}, \mathrm{Cu}$, and $\mathrm{Ti}$ in a $\mathrm{C}$ based matrix. In addition, evidence of an additional interfacial layer enriched in Cr was observed with an approx. thickness of $100 \mathrm{~nm}$. XPS analysis on the uncoated surface of the inner side of the window profile showed presence of $\mathrm{Cr}$ in the form of $\mathrm{Cr}(\mathrm{III}), \mathrm{Cr}(\mathrm{IV})$, and $\mathrm{Cr}(\mathrm{VI})$. TEM analysis of the interface at the coating and the Al substrate showed evidence of an intermetallic phase at the interface and heterogeneity in the surrounding interfacial $\mathrm{Cr}$ enriched layer. 
As mentioned earlier, recycling of $\mathrm{Al}$ has been shown to increase the level of impurities and trace elements leading to higher number of intermetallic phases. Chino et al. [28] studied solid state recycling of AA5083 and showed that higher amounts of Fe are present in the recycled alloy and higher weight loss in salt spray tests. Premendra et al. [29] studied commercially recycled AA5050 alloy and compared with that of a model AA5050 alloy and noted that a commercially recycled alloy with higher content of impurities manifested a wide range of heterogeneities and local changes which altered the electrochemical behaviour. In addition, it was presented that controlling the $\mathrm{Fe}$ content in the recycled alloy reduces the filiform corrosion susceptibility of the AA5xxx alloys that are widely used as architectural profiles.

The increase in constituent intermetallic phase particles (based on $\mathrm{Fe}$ ) upon recycling of $\mathrm{Al}$ alloys also leads to an increase in surface defects such as streaks and shingle while rolling (see Figure 3). Gjonnes et al. [22] attributed the formation of shingles on rolled Al alloys due to local adhesion and sticking, followed by deformation and rupture of the metal surface after passing through the deformation rolls. Vander voort et al. [30] showed that the difference in local number density of second phases or intermetallics on the Al surface causes local differences in temperature rise, and extent of deformation under rolling and thus leads to a heterogeneity in surface roughness causing streaks on the rolled $\mathrm{Al}$ surface. In general the defects on rolled $\mathrm{Al}$ alloys are reported to be formed mainly due to the presence of intermetallic phase particles that interact with the roll counter face and modify the local microstructure, texture and morphology of the Al metal under high shear forces [31].

Another critical aspect of rolled $\mathrm{Al}$ alloys is the high degree of surface localised deformation leading to rolling-in or incorporation of oxides and other impurities into the $\mathrm{Al}$ surface. Often referred to as a 'Beilby layer', as mentioned earlier, this sub-surface region is usually characterized by a very fine grain size and contains inclusions such as oxides and atmospheric contaminants like 
lubricants [32]. The severity of such surface defects and heterogeneities, increases with increasing intermetallic phases usually upon recycling, and highly affects the quality and control of the subsequent chemical or electrochemical surface finishing processing of the $\mathrm{Al}$ alloys [33].

The coated AA5006 window frame profile studied in this work, as characterized by elemental depth profiling using RF-GDOES (see Figure 14) and the EDS mapping using S-TEM (Figure 13), revealed presence of a $\mathrm{Cr}$ and $\mathrm{Si}$ rich interfacial layer at the metal-primer/base coat interface. This is also supported by the EDS data obtained from the surface of $\mathrm{Al}$ that is exposed after peeling off the blistered powder coating (see Table 2). Presence of this enriched $\mathrm{Cr}$ layer could be assumed to be due to the migration of $\mathrm{Cr}$ from a $\mathrm{Cr}$ and Silane containing primer which provides inhibition and passivating effect, for corrosion control of coated $\mathrm{Al}$ alloys surfaces (in form of chromated pigments, see Table 2 and Table 3) [34][35]. However, the XPS analysis presented in Figure 15 and Figure 16 on the uncoated AA5006 surface that has undergone just the pre-treatment and surface finishing process shows presence of $\mathrm{Cr}$ along with $\mathrm{Al}, \mathrm{Si}$ and $\mathrm{O}$. This confirms the presence of a $\mathrm{Cr}$ conversion coating process applied to the AA5006 surface prior to powder coating. The peak binding energy values derived from the high resolution $\mathrm{Cr} 2 p$ spectra presented in Table 4 correspond to those reported for a hexavalent $\mathrm{Cr}$ conversion coating which majorly has $\mathrm{Cr}(\mathrm{III})$ in the form of $\mathrm{Cr}_{2} \mathrm{O}_{3}$ and $\mathrm{Cr}(\mathrm{OH})_{3}$ [36]. The presence of $\mathrm{Cr}(\mathrm{IV})$ in the form of $\mathrm{CrO}_{2}$ can be attributed to $\mathrm{X}$-ray beam induced damage by reduction of $\mathrm{Cr}(\mathrm{VI})$ compounds, mainly $\mathrm{Cr}_{2} \mathrm{O}_{7}{ }^{2-}$ and $\mathrm{CrO}_{4}{ }^{2-}$ [37]. The presence of $\mathrm{Na}, \mathrm{Si}$, and $\mathrm{F}$ along with $\mathrm{Cr}$, and $\mathrm{O}$ in this conversion layer (Figure 15 and Figure 16) is due to $\mathrm{Si}$ and $\mathrm{F}$ based additives in the conversion coating bath. Fluorides are used in the conversion coating bath for etching the natural oxide on the $\mathrm{Al}$ surface that is to be conversion coated. $\mathrm{Na}$ and $\mathrm{Si}$ arise from the fluoride source (usually $\mathrm{NaF}$ or $\mathrm{Na}_{2} \mathrm{SiF}_{6}$ ), or from the $\mathrm{Cr}$ source (usually sodium dichromate) in the hexavalent $\mathrm{Cr}$ conversion coating bath [7]. In addition, $\mathrm{Si}$ enrichment can also occur due to improper de-smutting of the surface after an alkaline etching 
process of the Al surface. The $\mathrm{Si}$ present in the Aluminium substrate upon alkaline etching is usually saturated on the etched surface as smut, along with other elements that are insoluble in the alkaline etching bath [38][39]. Improper or insufficient acidic de-smutting process leads to incomplete removal of this smut and other cathodic intermetallic phases (such as those seen in Figure 12) at the surface, which also have been shown to cause heterogeneities and defects in the subsequent $\mathrm{Cr}$ based conversion coating process [40].

The nucleation and growth of chromate conversion coating on an AA2024 alloys was studied by Brown et al. [41] who observed that the coating growth varied according to the size, shape and composition of the intermetallic phase particles in the $\mathrm{Al}$ alloy. The formation of coating is influenced on the anodic or cathodic nature of the intermetallic particles with respect to the surrounding $\mathrm{Al}$ matrix, resulting in discrete nodule type morphology and preferential growth over microstructural defects such as cellular and grain boundaries. Campestrini et al. [42] studied the influence of different surface preparation on Alclad $2024 \mathrm{Al}$ alloys and showed that presence of a large number of cathodic intermetallic phases changes the conversion coating nucleation process from homogenous to heterogeneous, thus causing precipitation of $\mathrm{Cr}(\mathrm{OH})_{3}$ preferentially at the cathodic sites. This in turn, increases the attack by the chromating solution at the weaker sites on the growing conversion layer, resulting in a less dense conversion coating, hence less corrosion protection. Further, the structure and morphology of $\mathrm{Cr}$ conversion coatings has been studied using TEM by several authors, and is shown to have a dense nature with thickness varying in the range of 80-150 nm [43][44]. However, the morphology of the Cr conversion coating observed in Figure 12 shows that the conversion layer is inhomogeneous, not dense and has a mushy type morphology. This highly suggests a non-optimum conversion coating application process, insufficient coating time or improper pre-treatment (alkaline etching and acidic de-smutting) or cleaning of the surface prior to coating. 
The morphology of the corrosion on the $\mathrm{Al}$ metal closely resembled intergranular corrosion (Figure 10), and is localised at regions having higher number density of intermetallic phases and surface defects such as shingles and streaks. The higher amount of intermetallic phases usually rich in $\mathrm{Fe}$ and $\mathrm{Mn}$, also increase the cathodic activity of the surface electrochemically, thus increasing the corrosion rate and also localizing the corrosion attack, resulting in the observed IGC attack [45]. In general, the analysis performed here on the blistered coated AA5006 profiles reveals the relationship between the material surface and microstructural heterogeneities on the rolled $\mathrm{Al}$ profiles that leads to heterogeneity in the pre-treatment and the conversion coating. Failure of the coating occurred due to corrosion of the underlying AA5006 metal surface by ingress of $\mathrm{Cl}$. The process of corrosion was accelerated due to an inhomogeneous and defective $\mathrm{Cr}$ conversion coating resulting from higher number of surface defects such as streaks and shingles. The presence of these surface defects in higher number density is attributed to the presence of higher content of intermetallic particles that are usually associated with secondary $\mathrm{Al}$ or recycled $\mathrm{Al}$ material. Corrosion products accumulated at the interface of the metal and the powder coating, resulting in blistering of the applied powder coating. 


\section{Conclusions}

1. Blistering of coated AA5006 profiles occurred due to corrosion product accumulated at the metal coating interface.

2. AA5006 reference sheet material showed higher number density of intermetallic phase particles due to the recycled nature of the $\mathrm{Al}$ alloy.

3. $\mathrm{Cr}$ based conversion coating applied to the metal surface was defective and inhomogeneous due to surface defects.

4. Corrosion morphology closely resembled IGC type attack and was localised at sites with higher concentration of intermetallic phase particles.

5. Corrosion, and premature failure occurred due to presence of $\mathrm{Cl}$ in the service atmosphere, and accelerated due to processing and finishing defects and heterogeneities associated with metal recycling.

\section{Acknowledgements}

The authors would like to thank Dr. Felix Lampert (DTU, Denmark) for their discussions, and input related to XPS characterization and conversion coatings of Aluminium alloys.

\section{References}

[1] T. Dursun, C. Soutis, Recent developments in advanced aircraft aluminium alloys, Mater. Des. 56 (2014) 862-871. doi:10.1016/j.matdes.2013.12.002.

[2] W.S. Miller, L. Zhuang, J. Bottema, A.J. Wittebrood, P. De Smet, A. Haszler, A. Vieregge, Recent development in aluminium alloys for the automotive industry, Mater. Sci. Eng. A. 280 (2000) 37-49. doi:10.1016/S0921-5093(99)00653-X. 
[3] M. Leary, Materials selection and substitution using aluminium alloys, in: R.B.T.-F. of A.M. Lumley (Ed.), Fundam. Alum. Metall., Woodhead Publishing, 2011: pp. 784-827. doi:10.1533/9780857090256.3.784.

[4] C. Vargel, M. Jacques, M.P. Schmidt, Chapter A.1 - The Advantages of Aluminium, in: C.V.J.P.B.T.-C. of A. Schmidt (Ed.), Elsevier, Amsterdam, 2004: pp. 9-16. doi:http://dx.doi.org/10.1016/B978-008044495-6/50006-9.

[5] C. Vargel, Corrosion of Aluminium, Elsevier B.V., 2004. doi:10.1016/B978-0-08-0444956.X5000-9.

[6] G.W. Critchlow, D.M. Brewis, Review of surface pretreatments for aluminium alloys, Int. J. Adhes. Adhes. 16 (1996) 255-274. doi:10.1016/S0143-7496(96)00014-0.

[7] P.G. Sheasby, R. Pinner, S. Wernick, The Surface Treatment and Finishing of Aluminium and Its Alloys, 6th ed., ASM International; Finishing Publications, 2001.

[8] S.T. Abrahami, J.M.M. de Kok, H. Terryn, J.M.C. Mol, Towards Cr(VI)-free anodization of aluminum alloys for aerospace adhesive bonding applications: A review, Front. Chem. Sci. Eng. (2017) 1-18. doi:10.1007/s11705-017-1641-3.

[9] O. Gharbi, S. Thomas, C. Smith, N. Birbilis, Chromate replacement: what does the future hold?, Npj Mater. Degrad. 2 (2018) 12. doi:10.1038/s41529-018-0034-5.

[10] H. Leth-Olsen, K. Nisancioglu, Filiform corrosion of aluminium sheet. I. Corrosion behaviour of painted material, Corros. Sci. 40 (1998) 1179-1194. doi:10.1016/S0010938X(98)00026-2.

[11] H. Leth-Olsen, A. Afseth, K. Nisancioglu, Filiform corrosion of aluminium sheet. II. Electrochemical and corrosion behaviour of bare substrates, Corros. Sci. 40 (1998) 11951214. doi:10.1016/S0010-938X(98)00025-0.

[12] H. Leth-Olsen, J.H. Nordlien, K. Nisancioglu, Filiform corrosion of aluminium sheet. III. 
Microstructure of reactive surfaces, Corros. Sci. 40 (1998) 2051-2063. doi:10.1016/S0010938X(98)00094-8.

[13] J.B. Hess, Physical metallurgy of recycling wrought aluminum alloys, Metall. Trans. A. 14 (1983) 323-327. doi:10.1007/BF02644210.

[14] R. Ambat, A.J. Davenport, G.M. Scamans, A. Afseth, Effect of iron-containing intermetallic particles on the corrosion behaviour of aluminium, Corros. Sci. 48 (2006) 3455-3471. doi:10.1016/j.corsci.2006.01.005.

[15] G.M. Scamans, M.F. Frolish, W.M. Rainforth, Z. Zhou, Y. Liu, X. Zhou, G.E. Thompson, The ubiquitous Beilby layer on aluminium surfaces, Surf. Interface Anal. 42 (2010) 175-179. doi:10.1002/sia.3204.

[16] X. Zhou, Y. Liu, G.E. Thompson, G.M. Scamans, P. Skeldon, J.A. Hunter, Near-Surface Deformed Layers on Rolled Aluminum Alloys, Metall. Mater. Trans. A. 42 (2011) 13731385. doi:10.1007/s11661-010-0538-2.

[17] R. Ambat, A.J. Davenport, A. Afseth, G. Scamans, Electrochemical Behavior of the Active Surface Layer on Rolled Aluminum Alloy Sheet, J. Electrochem. Soc. 151 (2004) B53-B58. doi:10.1149/1.1635828.

[18] V.C. Gudla, K. Rechendorff, Z.I. Balogh, T. Kasama, R. Ambat, In-situ TEM investigation of microstructural evolution in magnetron sputtered $\mathrm{Al}-\mathrm{Zr}$ and $\mathrm{Al}-\mathrm{Zr}-\mathrm{Si}$ coatings during heat treatment, Mater. Des. 89 (2016) 1071-1078. doi:10.1016/j.matdes.2015.10.081.

[19] K. Bordo, V.C. Gudla, L. Peguet, A. Afseth, R. Ambat, Electrochemical profiling of multiclad aluminium sheets used in automotive heat exchangers, Corros. Sci. 131 (2018) 28-37. doi:10.1016/j.corsci.2017.11.011.

[20] S.T. Abrahami, J.M.M. de Kok, V.C. Gudla, R. Ambat, H. Terryn, J.M.C. Mol, Interface strength and degradation of adhesively bonded porous aluminum oxides, Npj Mater. Degrad. 
1 (2017) 8. doi:10.1038/s41529-017-0007-0.

[21] S.T. Abrahami, J.M.M.M. de Kok, V.C. Gudla, K. Marcoen, T. Hauffman, R. Ambat, J.M.C. Mol, H. Terryn, V.C. Gudla, K. Marcoen, R. Ambat, H. Terryn, S.T. Abrahami, FluorideInduced Interfacial Adhesion Loss of Nanoporous Anodic Aluminium Oxide Templates in Aerospace Structures, ACS Appl. Nano Mater. 1 (2018) acsanm.8b01361. doi:10.1021/acsanm.8b01361.

[22] L. Gjonnes, B. Andersson, Mechanisms of surface deformation during cold rolling of aluminium, J. Mater. Sci. 3 (1998) 2469-2476. doi:10.1023/A:1004328513471.

[23] V.C. Gudla, V.E. Johansen, S. Canulescu, J. Schou, R. Ambat, Simulation of Reflectance from White Anodised Aluminium Surfaces Using Polyurethane-TiO2 Composite Coatings, J. Mater. Sci. 50 (2015) 4565-4575. doi:DOI: 10.1007/s10853-015-9005-1.

[24] Z. Szklarska-Smialowska, Pitting corrosion of aluminum, Corros. Sci. 41 (1999) 1743-1767. doi:10.1016/S0010-938X(99)00012-8.

[25] A.J. Davenport, Y. Yuan, R. Ambat, B.J. Connolly, M. Strangwood, A. Afseth, G.M. Scamans, Intergranular Corrosion and Stress Corrosion Cracking of Sensitised AA5182, Mater. Sci. Forum. 519-521 (2006) 641-646. doi:10.4028/www.scientific.net/MSF.519521.641.

[26] S.T. Abrahami, T. Hauffman, J.M.M. de Kok, J.M.C. Mol, H. Terryn, XPS Analysis of the Surface Chemistry and Interfacial Bonding of Barrier-Type Cr(VI)-Free Anodic Oxides, J. Phys. Chem. C. 119 (2015) 19967-19975. doi:10.1021/acs.jpcc.5b05958.

[27] M.C. Biesinger, C. Brown, J.R. Mycroft, R.D. Davidson, N.S. McIntyre, X-ray photoelectron spectroscopy studies of chromium compounds, Surf. Interface Anal. 36 (2004) 1550-1563. doi:10.1002/sia.1983.

[28] Y. Chino, M. Mabuchi, S. Otsuka, K. Shimojima, H. Hosokawa, Y. Yamada, C. Wen, H. 
Iwasaki, Corrosion and mechanical properties of recycled 5083 aluminum alloy by solid state recycling, Mater. Trans. 44 (2003) 1284-1289. doi:10.2320/matertrans.44.1284.

[29] P. Premendra, H. Terryn, J.M.C. Mol, J.H.W. De Wit, L. Katgerman, A comparative electrochemical study of commercial and model aluminium alloy (AA5050), Mater. Corros. 60 (2009) 399-406. doi:10.1002/maco.200805145.

[30] G. Vander Voort, B. Suárez Peña, J. Asensio Lozano, Microstructure Investigations of Streak Formation in 6063 Aluminum Extrusions by Optical Metallographic Techniques, Microsc. Microanal. 19 (2013) 276-284. doi:10.1017/S143192761300010X.

[31] H. Zhu, X. Zhang, M.J. Couper, A.K. Dahle, Effect of primary intermetallic particles on surface microstructure and appearance of aluminium extrusions, Mater. Chem. Phys. 113 (2009) 401-406. doi:10.1016/j.matchemphys.2008.07.109.

[32] Premendra, B.S. Tanem, J.M.C. Mol, H. Terryn, J.H.W. DeWit, L. Katgerman, A combined TEM and SKPFM investigation of the surface layers on rolled AA5050 aluminium alloy using ultra-microtomy, Surf. Interface Anal. 40 (2008) 1157-1163. doi:10.1002/sia.2857.

[33] K. Nisancioglu, Electrochemical Behavior of Aluminum-Base Intermetallics Containing Iron, J. Electrochem. Soc. 137 (1990) 69. doi:10.1149/1.2086441.

[34] M.W. Kendig, R.G. Buchheit, Corrosion inhibition of aluminum and aluminum alloys by soluble chromates, chromate coatings, and chromate-free coatings, Corrosion. 59 (2003) 379-400. doi:10.5006/1.3277570.

[35] D.O. Flamini, M. Trueba, S.P. Trasatti, Aniline-based silane as a primer for corrosion inhibition of aluminium, Prog. Org. Coatings. $74 \quad$ (2012) 302-310. doi:10.1016/j.porgcoat.2011.11.011.

[36] A.E. Hughes, R.J. Taylor, B.R.W. Hinton, Chromate Conversion Coatings on 2024 Al Alloy, Surf. Interface Anal. $25 \quad$ (1997) 223-234. doi:10.1002/(SICI)1096- 
9918(199704)25:4<223::AID-SIA225>3.0.CO;2-D.

[37] D. Chidambaram, G.P. Halada, C.R. Clayton, Development of a technique to prevent radiation damage of chromate conversion coatings during X-ray photoelectron spectroscopic analysis, Appl. Surf. Sci. 181 (2001) 283-295. doi:10.1016/S0169-4332(01)00433-0.

[38] O. Lunder, K.F. Heen, K. Nisancioglu, Pretreatment of aluminum alloy 6060 by selective removal surface intermetallics, Corrosion. 60 (2004) 622-631.

[39] Y. Guo, G.S. Frankel, Characterization of trivalent chromium process coating on AA2024T3, Surf. Coatings Technol. 206 (2012) 3895-3902. doi:10.1016/j.surfcoat.2012.03.046.

[40] G.M. Brown, K. Shimizu, K. Kobayashi, G.E. Thompson, G.C. Wood, The morphology, structure and mechanism of growth of chemical conversion coatings on aluminium, Corros. Sci. 33 (1992) 1371-1385. doi:10.1016/0010-938X(92)90178-6.

[41] G.M. Brown, K. Kobayashi, Nucleation and Growth of a Chromate Conversion Coating on Aluminum Alloy AA 2024-T3, J. Electrochem. Soc. 148 (2001) B457. doi:10.1149/1.1409544.

[42] P. Campestrini, E.P.M. Van Westing, J.H.W. De Wit, Influence of surface preparation on performance of chromate conversion coatings on Alclad 2024 aluminium alloy - Part I: Nucleation and growth, Electrochim. Acta. 46 (2001) 2553-2571. doi:10.1016/S00134686(01)00475-3.

[43] Q. Meng, G.S. Frankel, Characterization of chromate conversion coating on AA7075-T6 aluminum alloy, Surf. Interface Anal. 36 (2004) 30-42. doi:10.1002/sia.1643.

[44] Y. Liu, P. Skeldon, G.E. Thompson, H. Habazaki, K. Shimizu, Chromate conversion coatings on aluminium: Influences of alloying, Corros. Sci. 46 (2004) 297-312. doi:10.1016/S0010-938X(03)00157-4.

[45] A.J. Davenport, Y. Yuan, R. Ambat, B.J. Connolly, M. Strangwood, A. Afseth, G.M. 
Scamans, Intergranular Corrosion and Stress Corrosion Cracking of Sensitised AA5182, Mater. Sci. Forum. (2009). doi:10.4028/www.scientific.net/msf.519-521.641. 


\section{Figures}

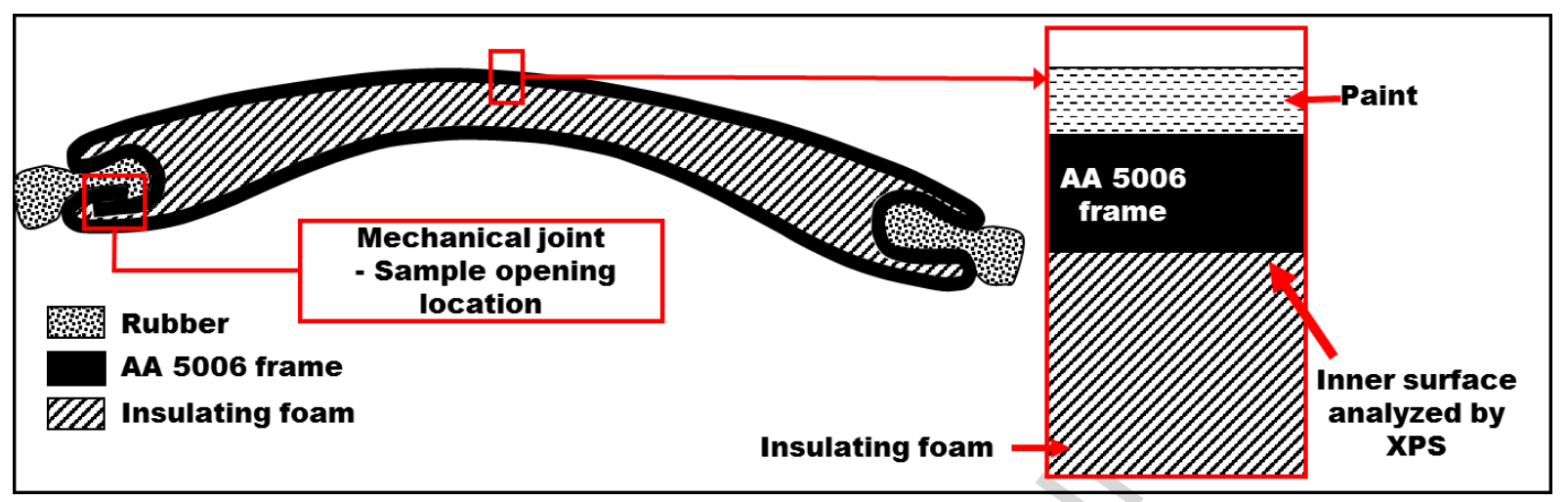

Figure 1: Schematic representation showing the cross-section of the AA5006 coated window frame profiles, showing the profile of the Al frame with the inner insulating foam and the external rubber at the edges. The mechanical joint on the left was used to open the profile and expose the inner uncoated AA5006 surface for XPS analysis.

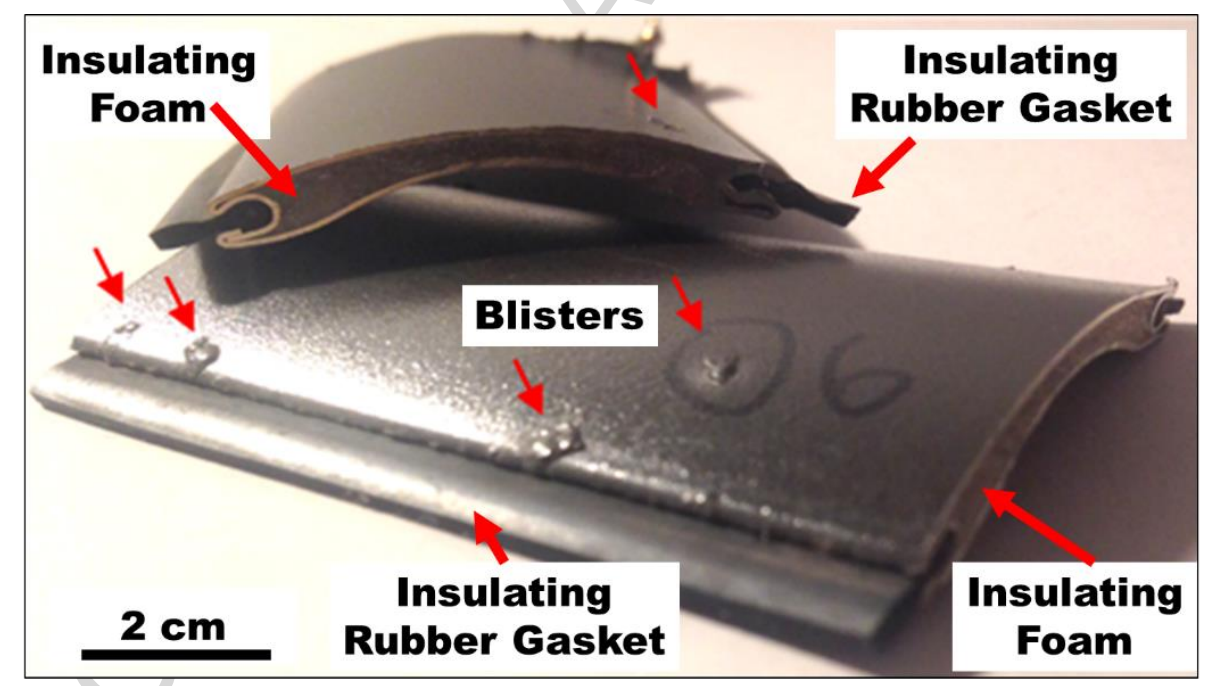

Figure 2: Representative digital photograph of coated aluminium window profile showing the geometry of the profile, the insulating rubber gasket foam and blisters. 

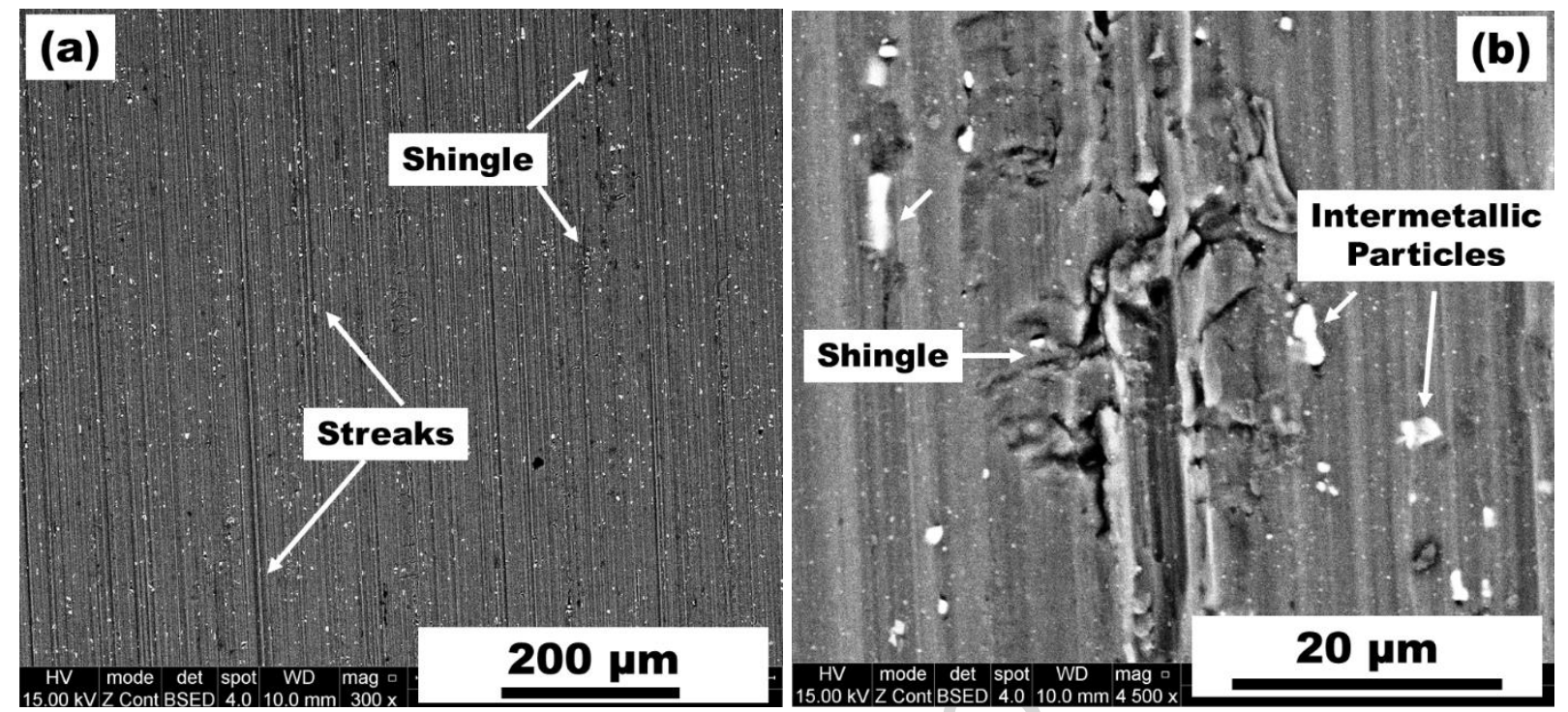

Figure 3: Back scattered electron images of the Aluminium AA5006 (reference) sheets prior to coating at (a) lower magnification and (b) higher magnification, showing a high number density of bright appearing intermetallic phase particles, surface streaks, and 'shingle' defects associated with agglomerated intermetallic particles.

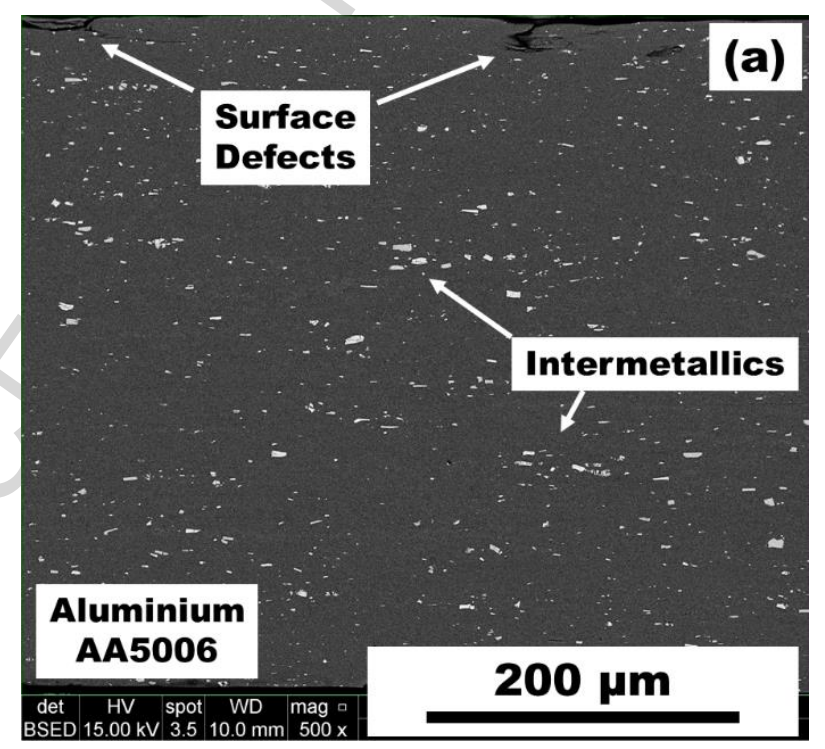

Figure 4: Back scattered electron image of the cross section of the AA5006 reference sheet material showing the intermetallic phases and the surface defects. 

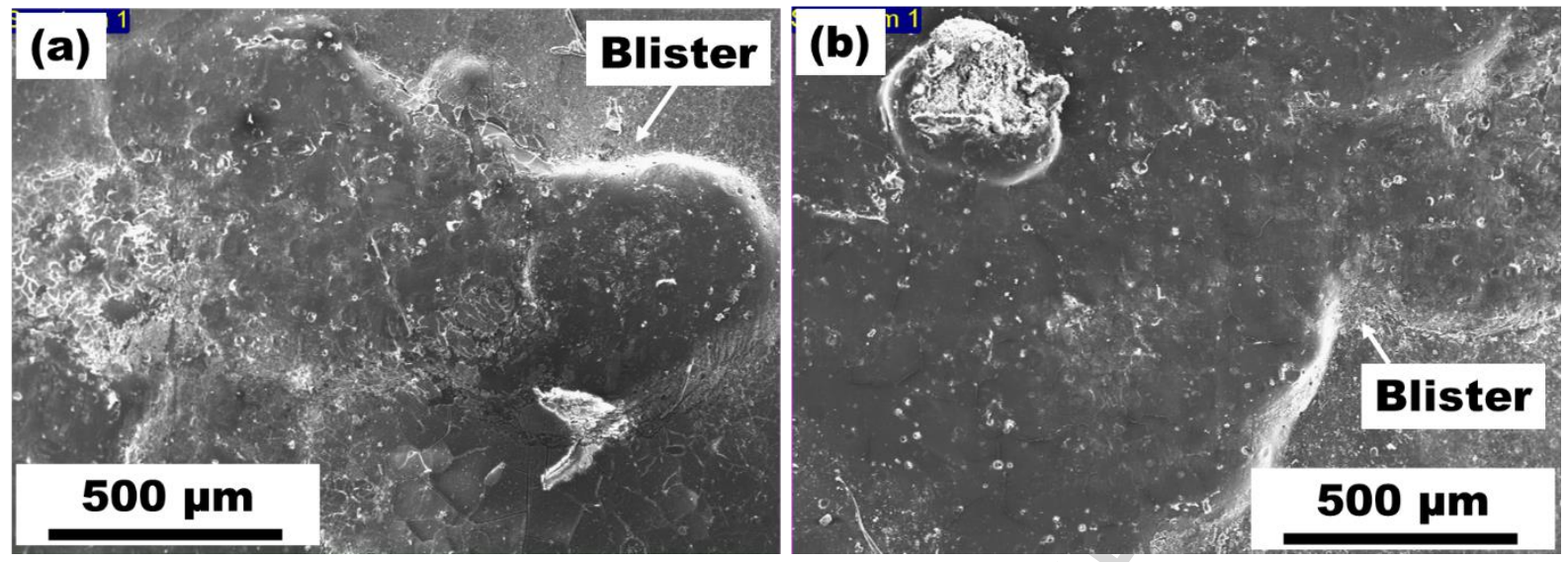

Figure 5: Secondary electron images of blisters on the coated AA5006 profiles.

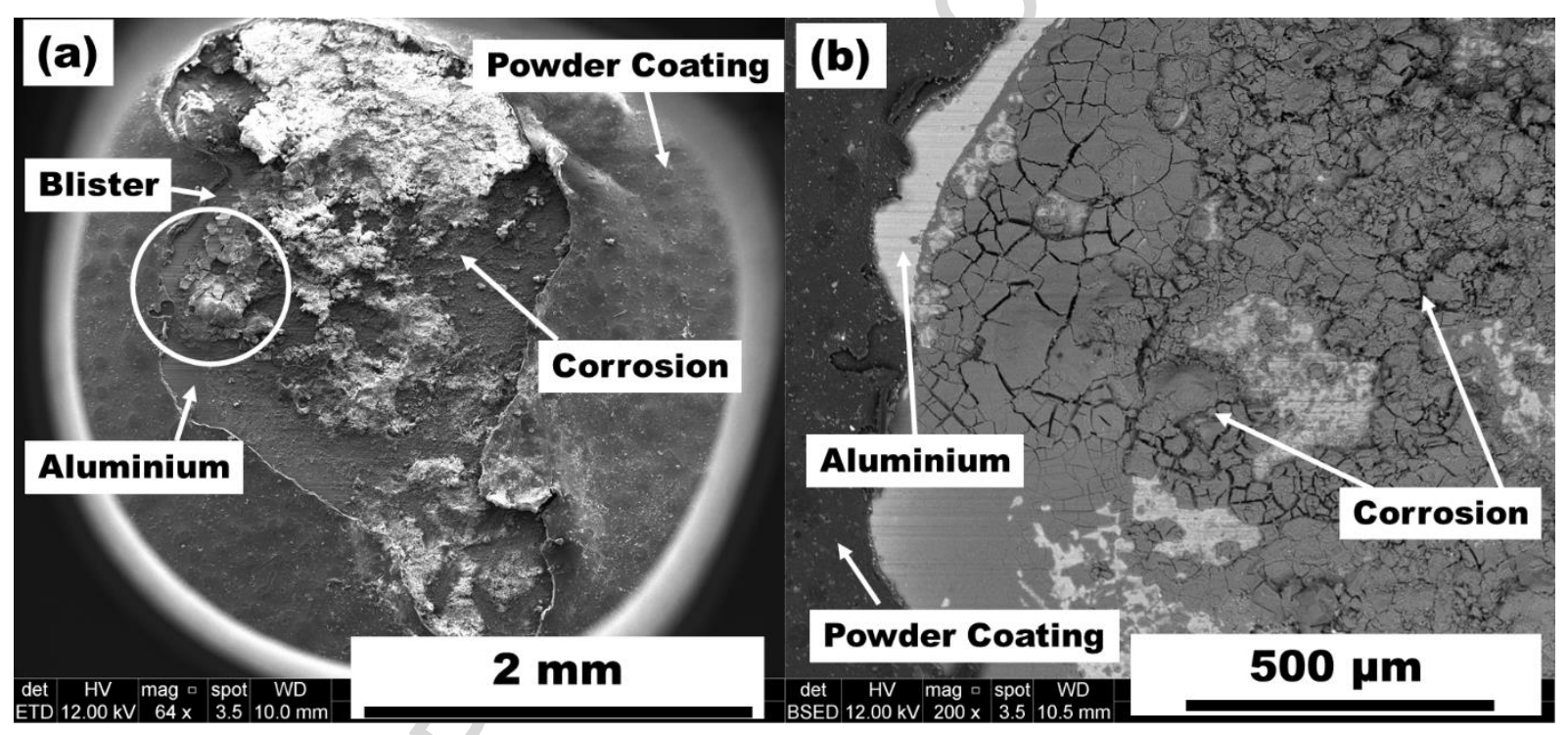

Figure 6: (a) Secondary electron topography image and (b) back scattered electron image of the circular region marked in (a) from the blistered region, after surgical removal of the top coating layer, showing corrosion products on the surface of the AA5006 profile. 


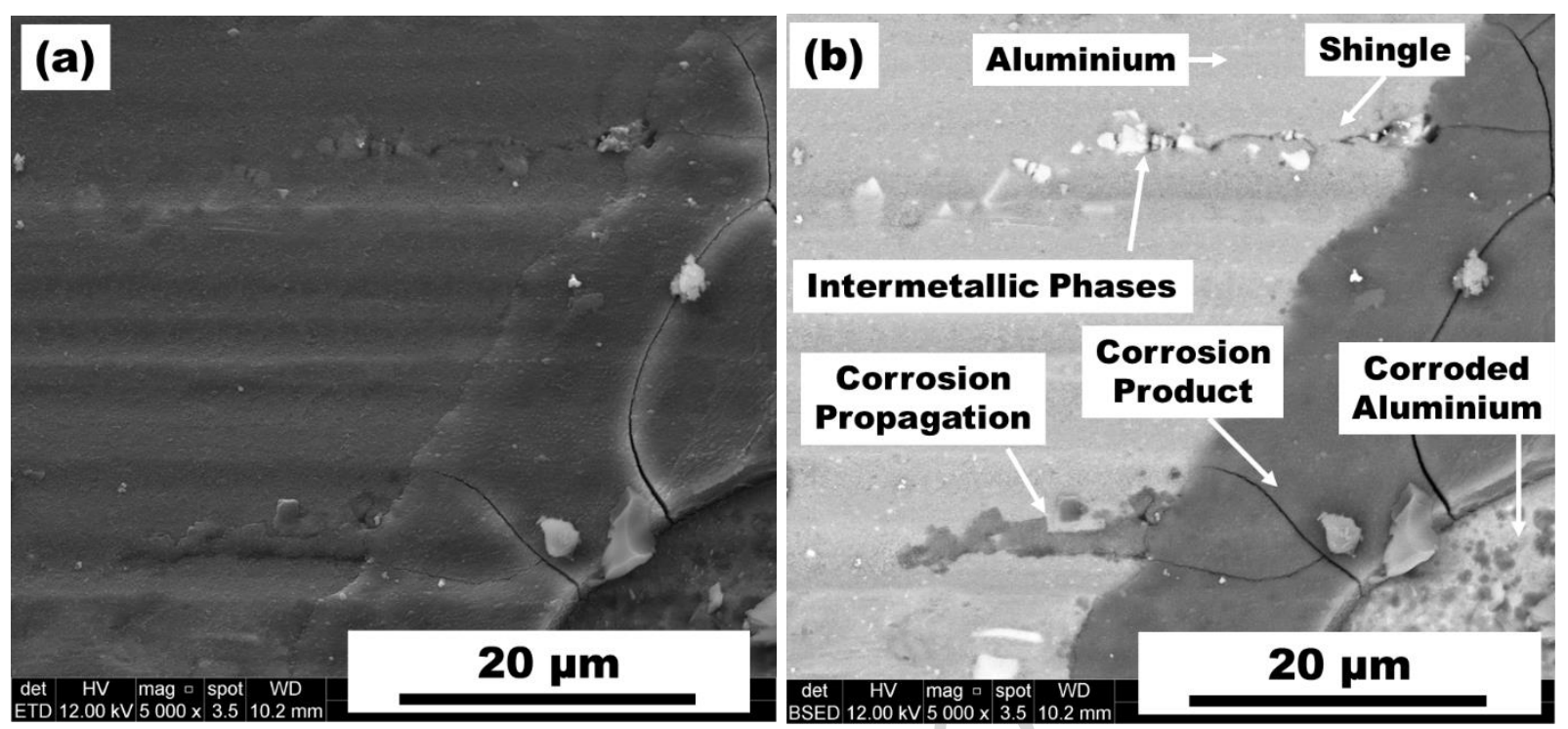

Figure 7: (a) Secondary electron and (b) back scattered electron images of the corrosion front, observed under the blister, showing one instance of preferential propagation of corrosion along the defects in the rolling direction on the AA5006 profile.

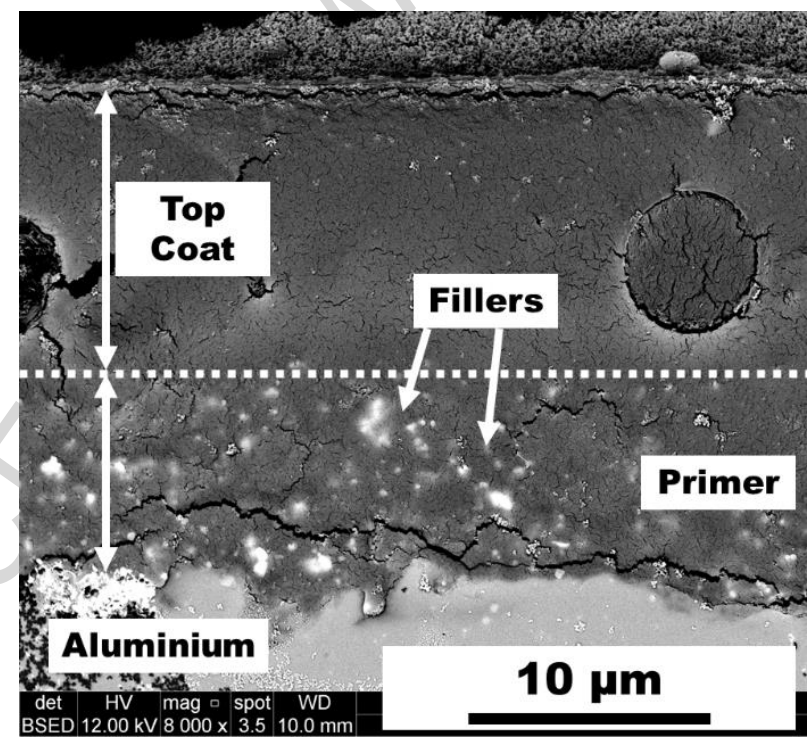

Figure 8: SEM back scattered electron image of the coated Aluminium profile, showing the Aluminium substrate, the primer with the fillers, and the top coat. 

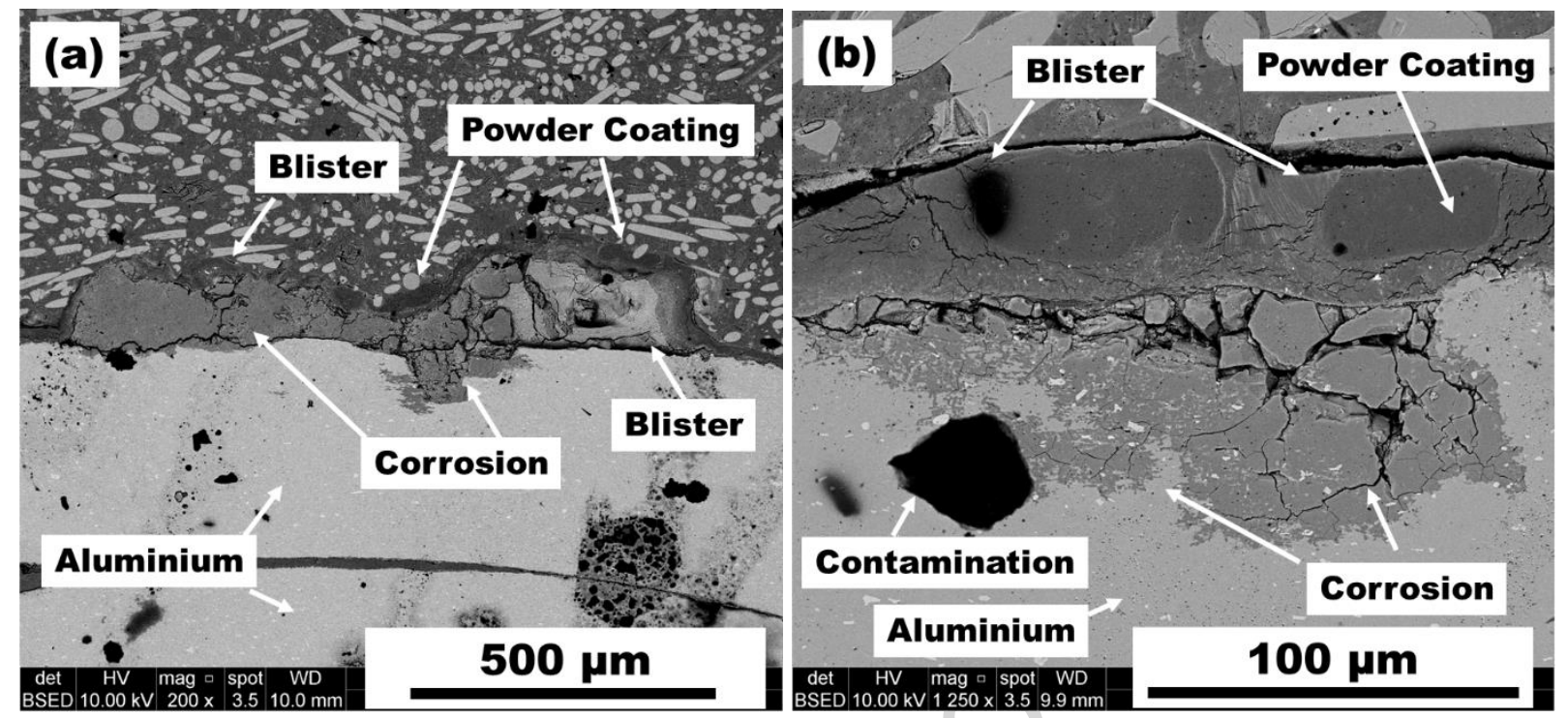

Figure 9: SEM back scattered electron images of cross-section of blistered regions on the coated AA5006 profiles, showing the coating, blisters, corrosion products and the corrosion propagation into the AA5006 profile.
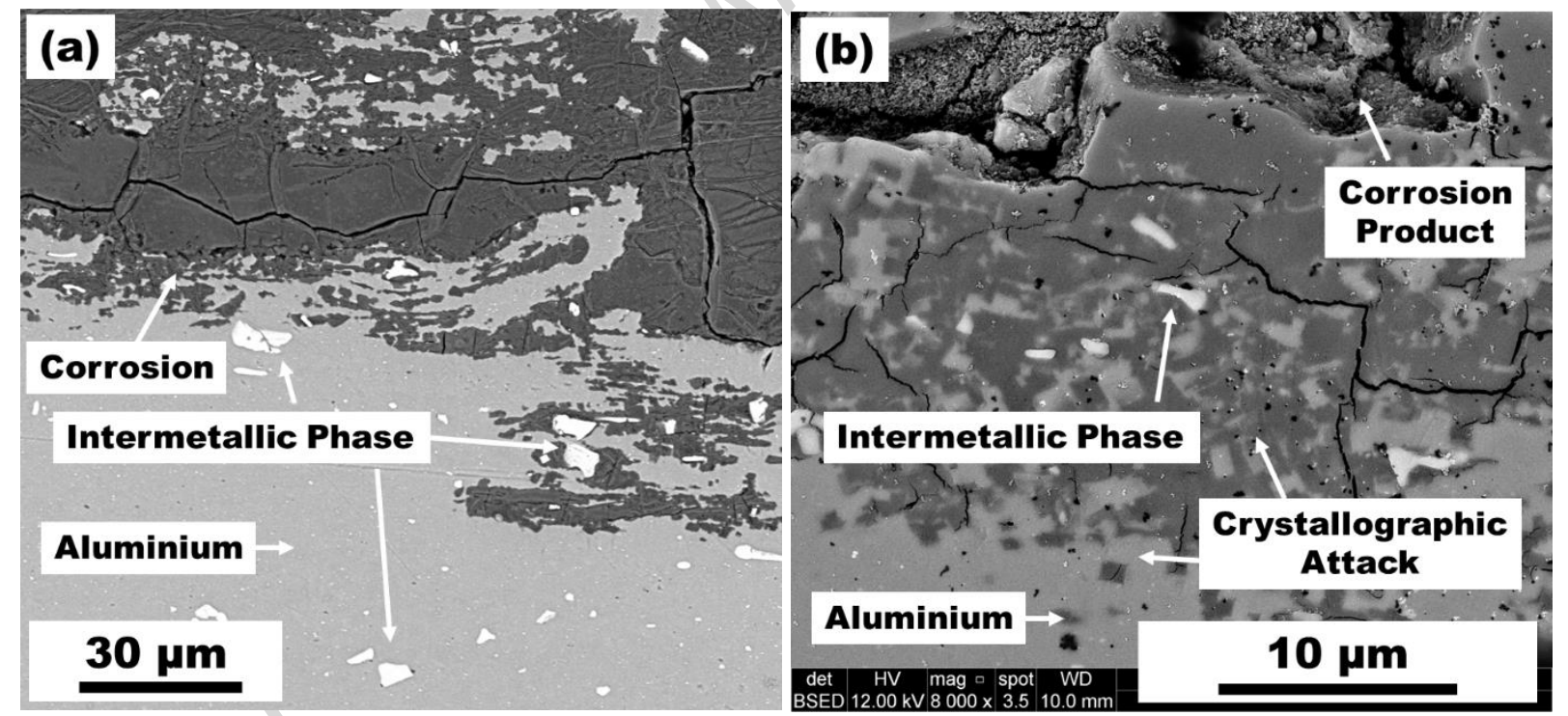

Figure 10: SEM backscattered electron images of cross-section of blistered regions, showing corrosion of the AA5006 coated profile displaying (a) lateral propagation of corrosion and (b) crystallographic dissolution of the Aluminium substrate. 


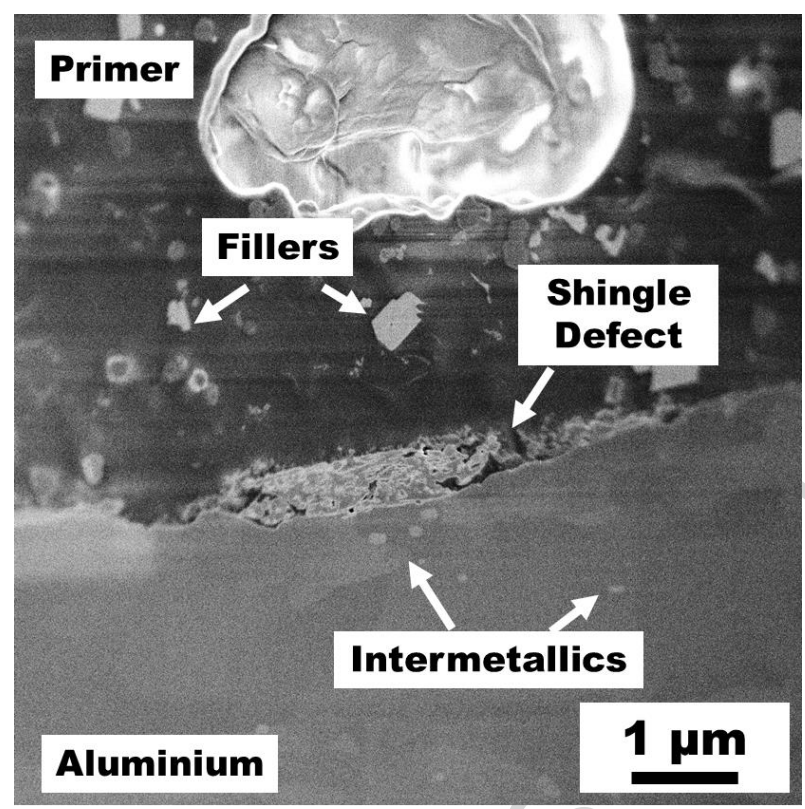

Figure 11: Secondary electron image from the in-situ focused ion beam milled cross-section of the coated AA5006 profile, showing the Aluminium substrate, the primer with the fillers and a 'shingle defect' at the interface of the metal and the coating.
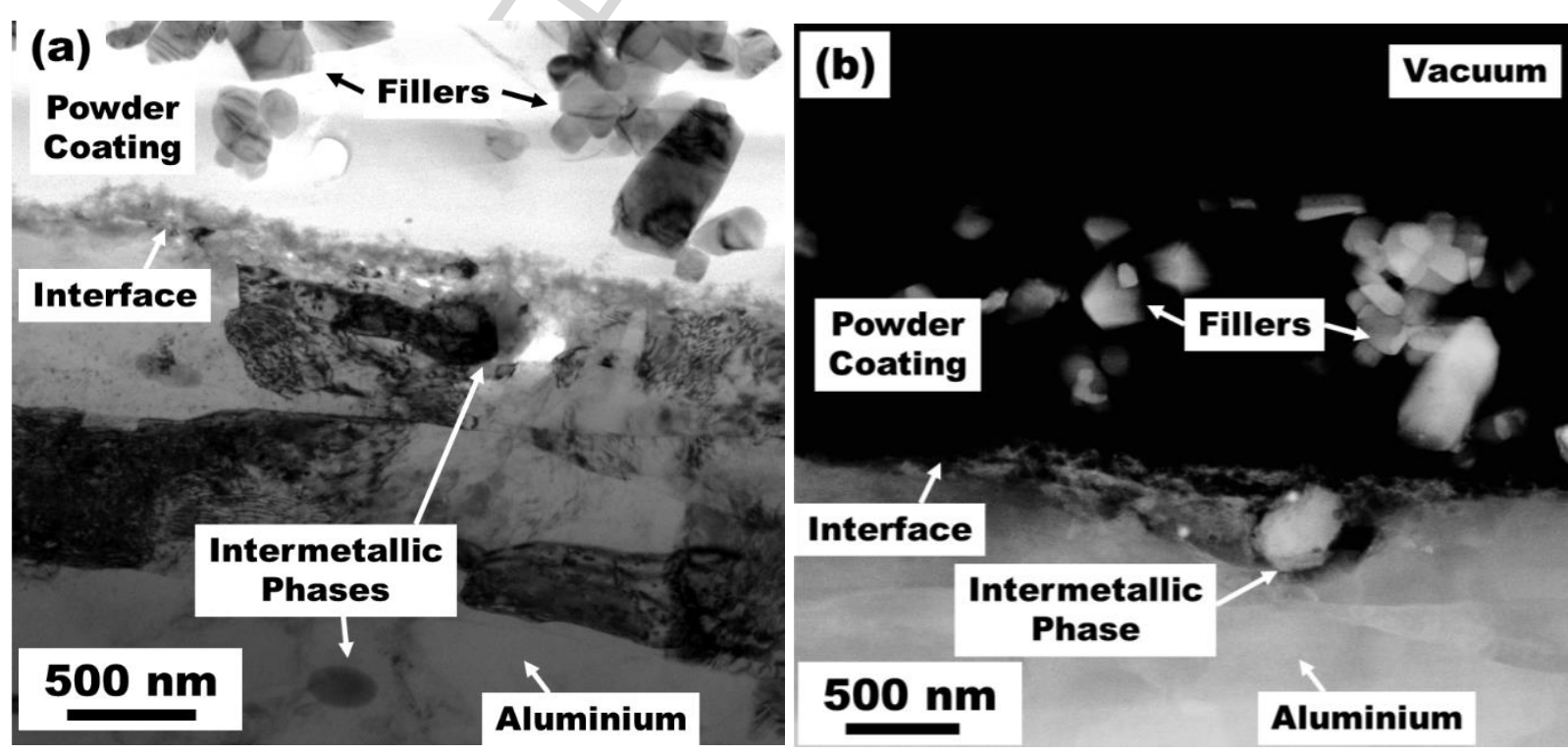

Figure 12: (a) Bright field transmission electron micrograph, and (b) high angle annular dark field (HAADF) scanning transmission electron micrograph of the FIB prepared thin film 
lamella, from the coated AA5006 profiles, showing the Al substrate, the interface with the coating and the fillers in the applied coating. Note the presence of an intermetallic phase particle at the interface with the coating and the porous region surrounding it. 

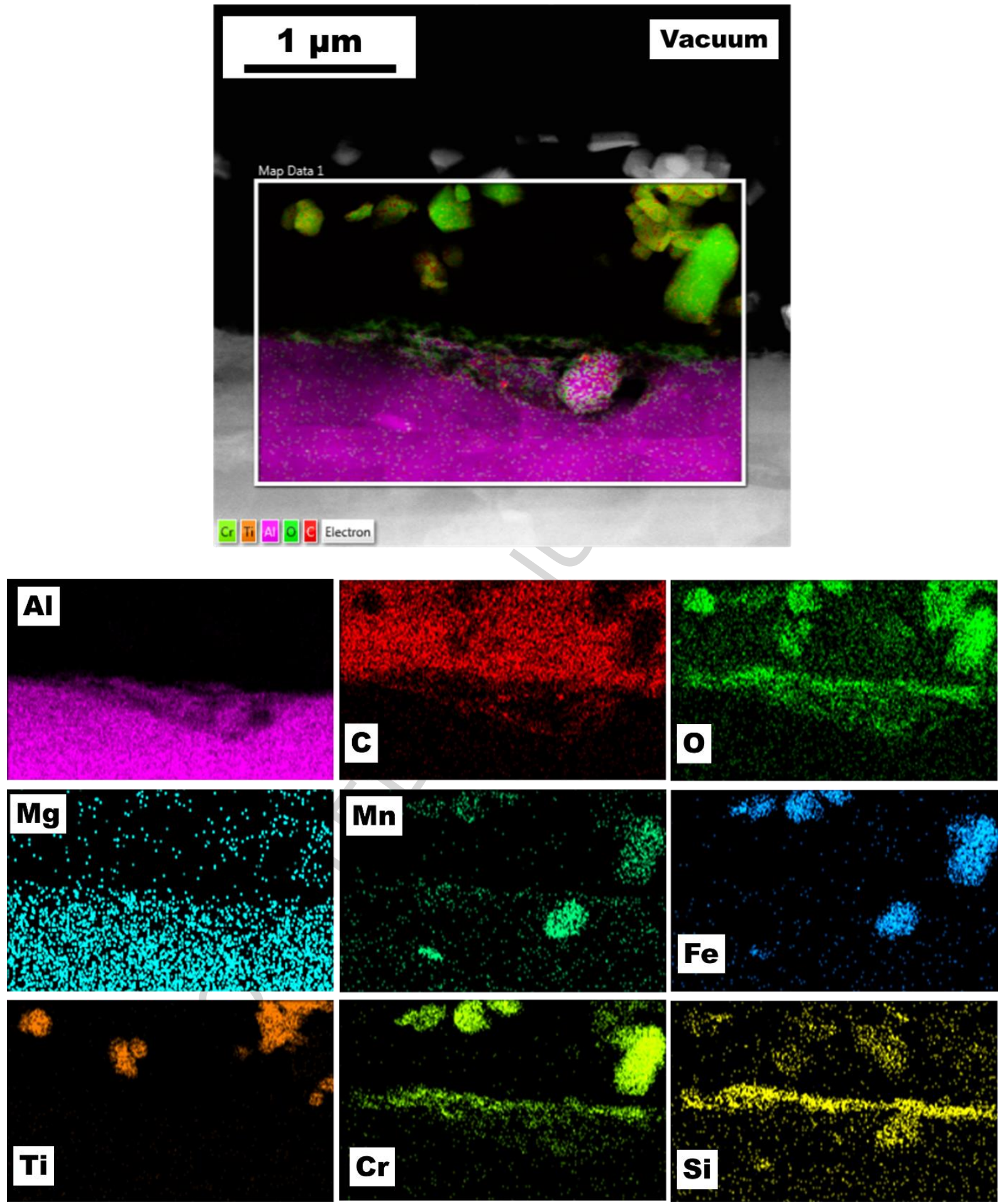

Figure 13: STEM HAADF micrograph with EDS Cr, Ti, Al, O and C elemental map overlay, and individual elemental maps for $\mathrm{Al}, \mathrm{C}, \mathrm{O}, \mathrm{Mg}, \mathrm{Mn}, \mathrm{Fe}, \mathrm{Ti}, \mathrm{Cr}$ and $\mathrm{Si}$. 


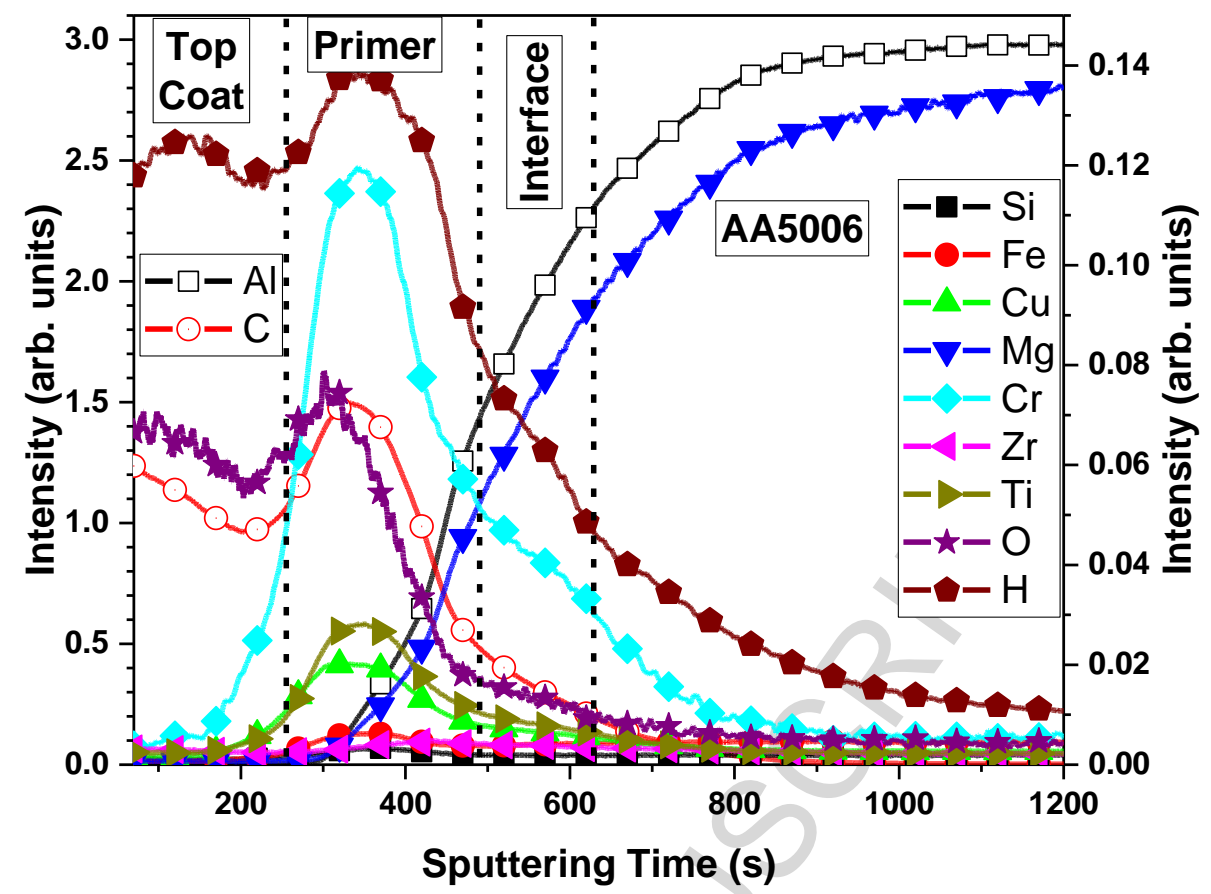

Figure 14: RF-GDOES elemental sputter depth profile obtained from the coated AA5006 surface.

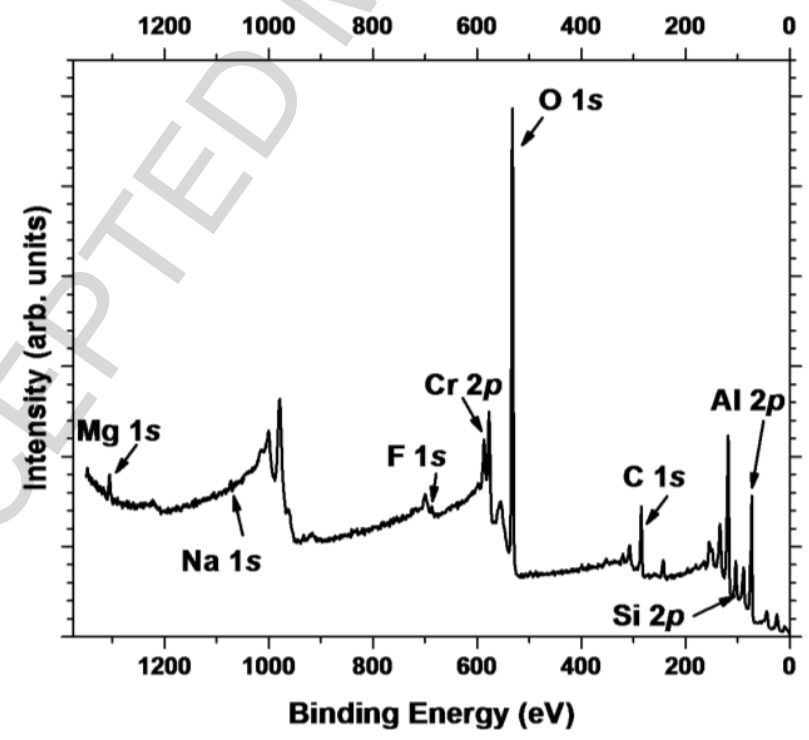

Figure 15: XPS survey scan obtained from the uncoated AA5006 surface showing the major identifiable elements present on the surface. 

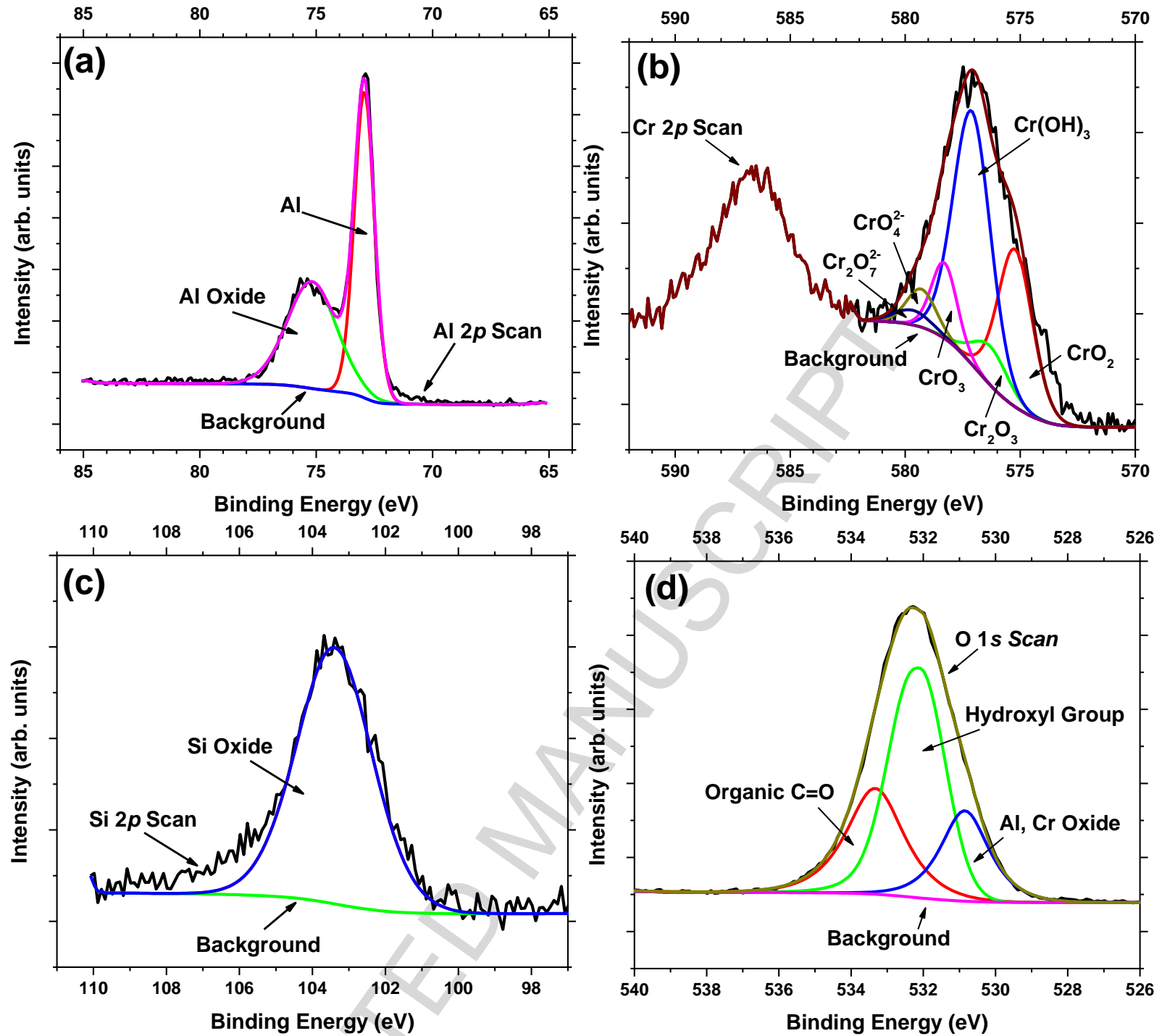

Figure 16: High resolution XPS spectrum for (a) Al $2 p$, (b) $\mathrm{Cr} 2 p$, (c) Si $2 p$, and (d) $\mathrm{O} 1 s$ obtained from the uncoated surface of AA5006 profile.

Figures that may be in color reproduction, online only:

Figure 1, figure 2, figure 13, figure 14, figure 16. 
Table 1: Chemical composition of EN AW $5006 \mathrm{H49}$ alloy in wt. \%, remaining is Aluminium.

\begin{tabular}{|c|c|c|c|c|c|c|c|c|c|c|}
\hline Alloy & Cr & Cu & Fe & Mg & Mn & Si & Ti & Zn & $\begin{array}{c}\text { Others, } \\
\text { each }\end{array}$ & $\begin{array}{c}\text { Others, } \\
\text { total }\end{array}$ \\
\hline AA5006 & $\leq 0.1$ & $\leq 0.1$ & $\leq 0.8$ & $0.8-1.3$ & $0.4-0.8$ & $\leq 0.4$ & $\leq 0.1$ & $\leq 0.25$ & $\leq 0.005$ & $\leq 0.15$ \\
\hline
\end{tabular}

Table 2: SEM EDS elemental analysis (in wt.\%) of the various features observed on the blistered AA5006 window profiles.

\begin{tabular}{|c|c|c|c|c|c|c|c|c|c|c|c|c|c|c|}
\hline $\begin{array}{r}S \\
\text { of } d \\
\text { featur }\end{array}$ & $\begin{array}{l}\text { EM-EDS } \\
\text { ifferent } \\
\text { es (wt. \%) }\end{array}$ & 0 & $\mathbf{a}^{\mathrm{N}}$ & $\mathrm{g}^{\mathrm{N}}$ & $\mathrm{I}^{\mathrm{A}}$ & $i^{S}$ & $\mathbf{S}$ & $1^{C}$ & 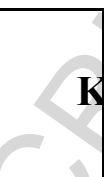 & i & $\mathbf{r}$ & n & $\mathrm{e}^{\mathbf{F}}$ & $\mathbf{u}^{\mathbf{C}}$ \\
\hline $\begin{array}{l}\quad F i \\
\text { gure } \\
7(b)\end{array}$ & \begin{tabular}{|c|} 
Expo \\
sed metal \\
under \\
blister
\end{tabular} & $\begin{array}{c}7 \\
.0 \pm 0 \\
6\end{array}$ & & $\begin{array}{r}0 \\
.7 \pm 0 . \\
1\end{array}$ & $\left|\begin{array}{r}8 \\
7.6 \pm 0 \\
.1\end{array}\right|$ & $\begin{array}{c}1 \\
4 \pm 0 . \\
2\end{array}$ & & & & & $\begin{array}{c}3 \\
.2 \pm 0 . \\
9\end{array}$ & & & \\
\hline $\begin{array}{l}\quad \text { Fi } \\
\text { gure } \\
7(b)\end{array}$ & \begin{tabular}{|c|} 
Corr \\
osion \\
product \\
under \\
blister
\end{tabular} & \begin{tabular}{|r}
6 \\
$4.9 \pm 0$ \\
.3
\end{tabular} & & & $\begin{array}{r}3 \\
3.5 \pm 0 \\
.2\end{array} \mid$ & & $\begin{array}{r}0 \\
.9 \pm 0 . \\
1\end{array}$ & $\begin{array}{c}0 \\
.8 \pm 0 . \\
1\end{array}$ & & & & & & \\
\hline $\begin{array}{r}F i \\
\text { gure } 8\end{array}$ & $\begin{array}{r}\text { Prim } \\
\text { er Layer }\end{array}$ & $\begin{array}{r}5 \\
1.4 \pm 7 \\
.3\end{array}$ & & & $\begin{array}{c} \pm \\
1.8\end{array}$ & $\begin{array}{r}4 \\
4 \pm 1 \\
0\end{array}$ & .5 & .3 & & $\left|\begin{array}{r}1 \\
7.5 \pm 2 \\
.4\end{array}\right|$ & $\begin{array}{r}9 \\
.3 \pm 1 \\
5\end{array}$ & & $\begin{array}{c}6 \\
3 \pm 0 \\
6\end{array}$ & .5 \\
\hline $\begin{array}{l}\quad \text { Fi } \\
\text { gure } \\
\text { 9(a) }\end{array}$ & \begin{tabular}{|c|} 
Corr \\
osion \\
product \\
over \\
metal
\end{tabular} & $\begin{array}{r}5 \\
9.2 \pm 0 \\
.5\end{array}$ & & & $\begin{array}{r}3 \\
7.4 \pm 0 \\
.8\end{array}$ & $\begin{array}{c}0 \\
6 \pm 0 . \\
1\end{array}$ & $\begin{array}{r}0 \\
.7 \pm 0 . \\
1\end{array}$ & $\begin{array}{c}1 \\
.6 \pm 0 . \\
2\end{array}$ & & & & & & \\
\hline $\begin{array}{l}\quad \text { Fi } \\
\text { gure } \\
\text { 9(b) }\end{array}$ & $\begin{array}{l}\quad \text { Corr } \\
\text { oded } \\
\text { metal }\end{array}$ & $\begin{array}{r}5 \\
6.2 \pm 0 \\
.7\end{array}$ & $.5^{0}$ & .3 & $\begin{array}{r}3 \\
7.6 \pm 0 \\
.5\end{array} \mid$ & $\begin{array}{r}0 \\
.6 \pm 0 . \\
1\end{array}$ & .40 & $\begin{array}{r}3 \\
.2 \pm 0 . \\
1\end{array}$ & $\begin{array}{r}0 \\
.3 \pm 0 . \\
1\end{array}$ & & & $\begin{array}{r}0 \\
.4 \pm 0 . \\
2\end{array}$ & $.4^{0}$ & \\
\hline
\end{tabular}

Table 3: TEM-EDS elemental composition (in at.\%) of different features observed in the coated AA5006 profile. 


\begin{tabular}{|c|c|c|c|c|c|c|c|c|c|}
\hline $\begin{array}{l}\text { Region of } \\
\text { Interest }\end{array}$ & $\mathbf{O}$ & Mg & Al & $\mathbf{S i}$ & $\mathbf{T i}$ & $\mathrm{Cr}$ & Mn & $\mathbf{F e}$ & $\mathrm{Cu}$ \\
\hline $\begin{array}{c}\text { Intermetallic at } \\
\text { interface }\end{array}$ & $\begin{array}{c}8.3 \pm 0 . \\
7\end{array}$ & & $\begin{array}{c}77.4 \pm 1 . \\
1\end{array}$ & $\begin{array}{c}4.4 \pm 0 . \\
2\end{array}$ & & 0.5 & $\begin{array}{c}4.8 \pm 0 . \\
3\end{array}$ & $\begin{array}{c}4.8 \pm 0 . \\
3\end{array}$ & \\
\hline $\begin{array}{l}\text { Intermetallic } \\
\text { in bulk }\end{array}$ & $\begin{array}{c}3.5 \pm 0 . \\
1\end{array}$ & & $\begin{array}{c}87.8 \pm 2 . \\
2\end{array}$ & $\begin{array}{c}3.1 \pm 0 . \\
7\end{array}$ & & & $\begin{array}{c}3.6 \pm 0 . \\
1\end{array}$ & $\begin{array}{c}2.1 \pm 0 . \\
3\end{array}$ & \\
\hline Al Matrix & & $\begin{array}{c}1.2 \pm 0 \\
1\end{array}$ & $\begin{array}{c}98.8 \pm 0 . \\
2\end{array}$ & & & & & & \\
\hline Fe based Filler & $\begin{array}{c}63.9 \pm \\
0.8\end{array}$ & & & $\begin{array}{c}1.1 \pm 0 . \\
3\end{array}$ & & $\begin{array}{c}19.6 \pm \\
0.3\end{array}$ & & $\begin{array}{c}6.0 \pm 0 . \\
4\end{array}$ & $\begin{array}{c}9.4 \pm \\
0.2\end{array}$ \\
\hline Ti based Filler & $\begin{array}{c}63.5 \pm \\
1.5\end{array}$ & & $1.7 \pm 0.2$ & $\begin{array}{c}1.8 \pm 0 . \\
6\end{array}$ & $\begin{array}{c}33.0 \pm 0 . \\
8\end{array}$ & $\sqrt{n}$ & & & \\
\hline $\begin{array}{l}\text { Region next to } \\
\text { Intermetallic at } \\
\text { surface (shingle } \\
\text { defect) }\end{array}$ & $\begin{array}{c}16.5 \pm \\
1.8\end{array}$ & $\begin{array}{c}2.4 \pm 0 . \\
9\end{array}$ & $\begin{array}{c}79.9 \pm 2 . \\
3\end{array}$ & $\begin{array}{c}0.6 \pm 0 . \\
1\end{array}$ & & $\begin{array}{c}0.5 \pm 0 \\
1\end{array}$ & & & \\
\hline
\end{tabular}

Table 4: Summary of fitting to the $\mathrm{Cr} 2 p_{3 / 2}$ spectra for the surface of AA5006 profile.

\begin{tabular}{|c|c|c|}
\hline Species & Peak BE $(\mathbf{e V})$ & \% \\
\hline $\mathbf{C r O}_{\mathbf{2}}$ & 575.2 & 27.48 \\
\hline $\mathbf{C r}_{\mathbf{2}} \mathbf{O}_{\mathbf{3}}$ & 576.3 & 6.97 \\
\hline $\mathbf{C r}(\mathbf{O H})_{\mathbf{3}}$ & 577.1 & 47.52 \\
\hline $\mathbf{C r O}_{\mathbf{3}}$ & 578.3 & 9.78 \\
\hline $\mathbf{C r O}_{\mathbf{4}}{ }^{2-}$ & 579.3 & 5.58 \\
\hline $\mathbf{C r}_{\mathbf{2}} \mathbf{O}_{\mathbf{7}}{ }^{2-}$ & 579.7 & 2.67 \\
\hline
\end{tabular}




\section{$\underline{\text { Research Highlights }}$}

- Blistering of coated AA5006 profiles occurred by corrosion product accumulation at metalcoating interface.

- AA5006 sheet metal had high number of intermetallic particles due to its recycled nature.

- $\mathrm{Cr}$ conversion coating on AA5006 was inhomogeneous due to surface defects and intermetallics on metal.

- Corrosion morphology resembled IGC and was localised at sites with higher concentration of intermetallics.

- Ingress of moisture and $\mathrm{Cl}$ to interface caused corrosion, which accelerated due to defective conversion layer and high intermetallics density. 


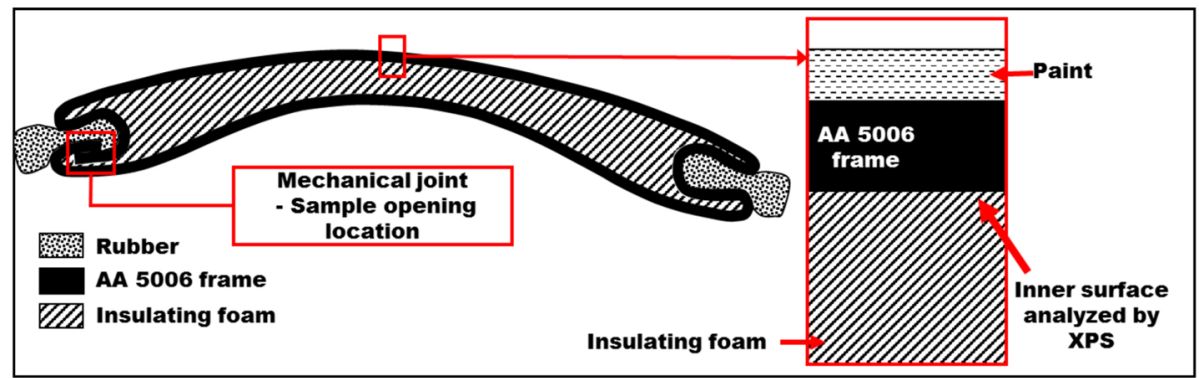

Figure 1 


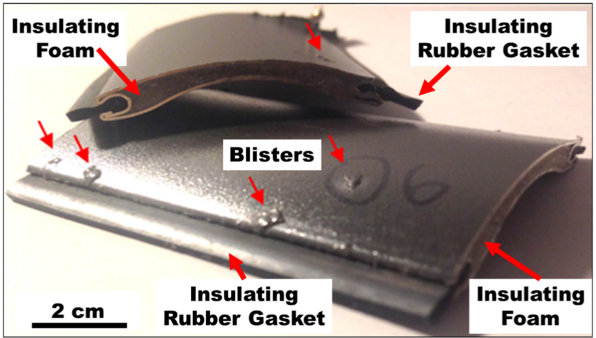

Figure 2 


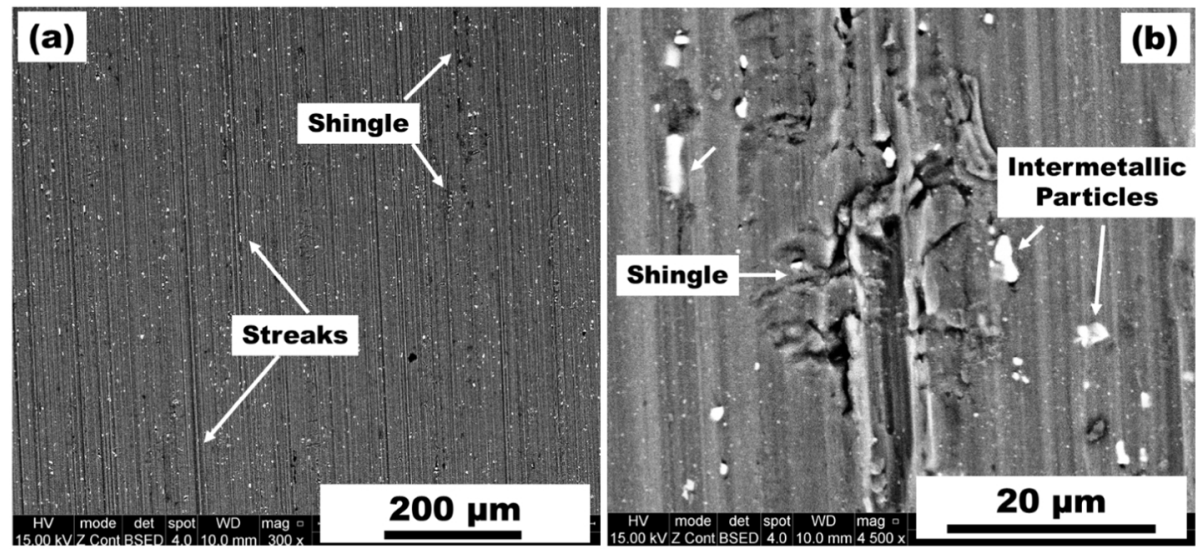

Figure 3 


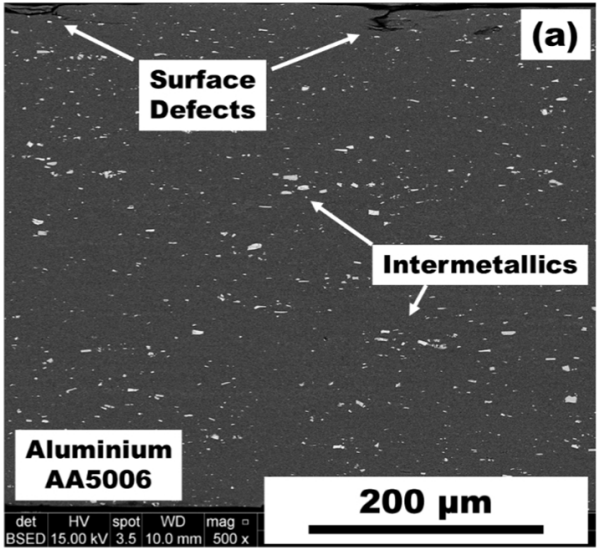

Figure 4 


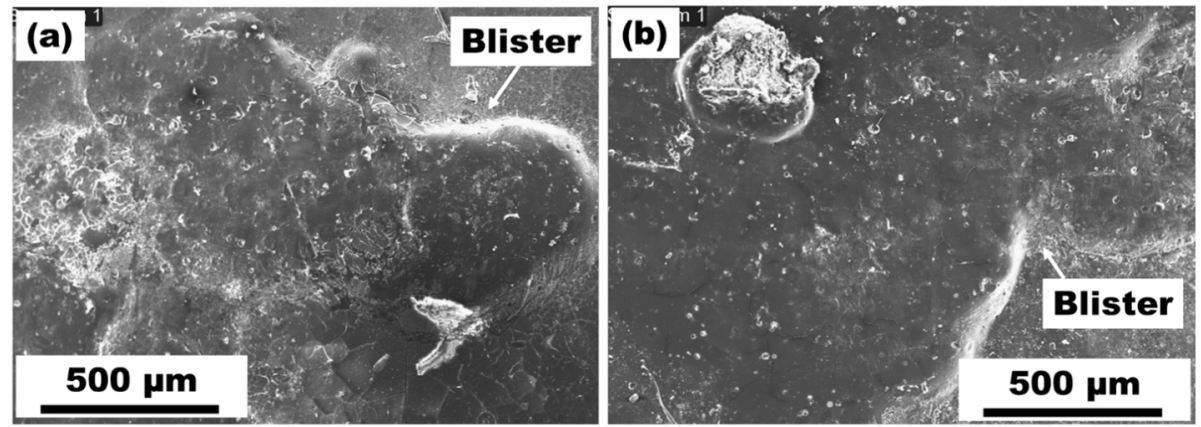

Figure 5 


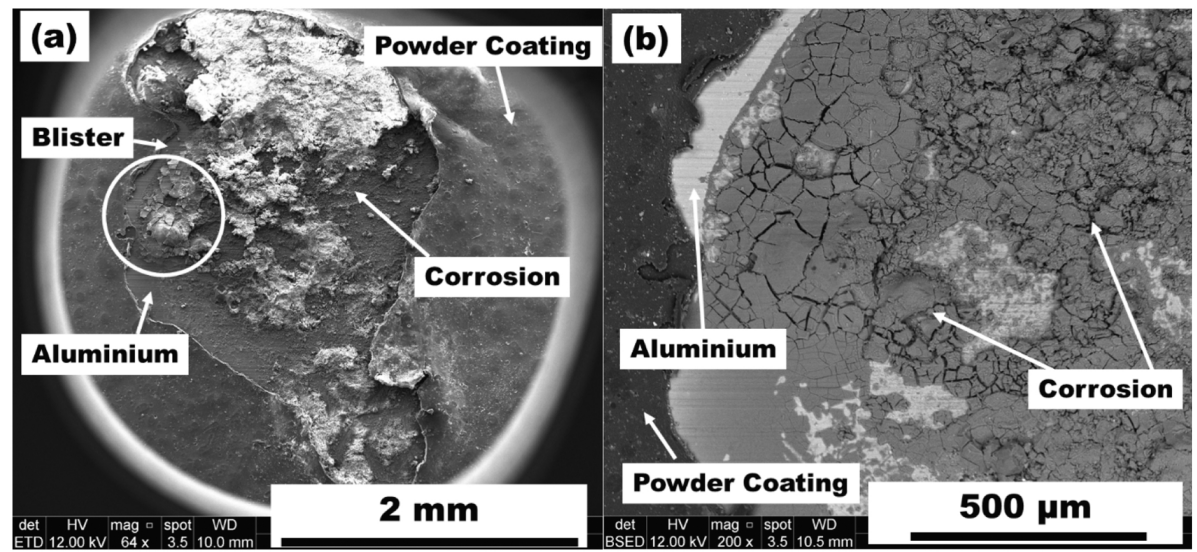

Figure 6 


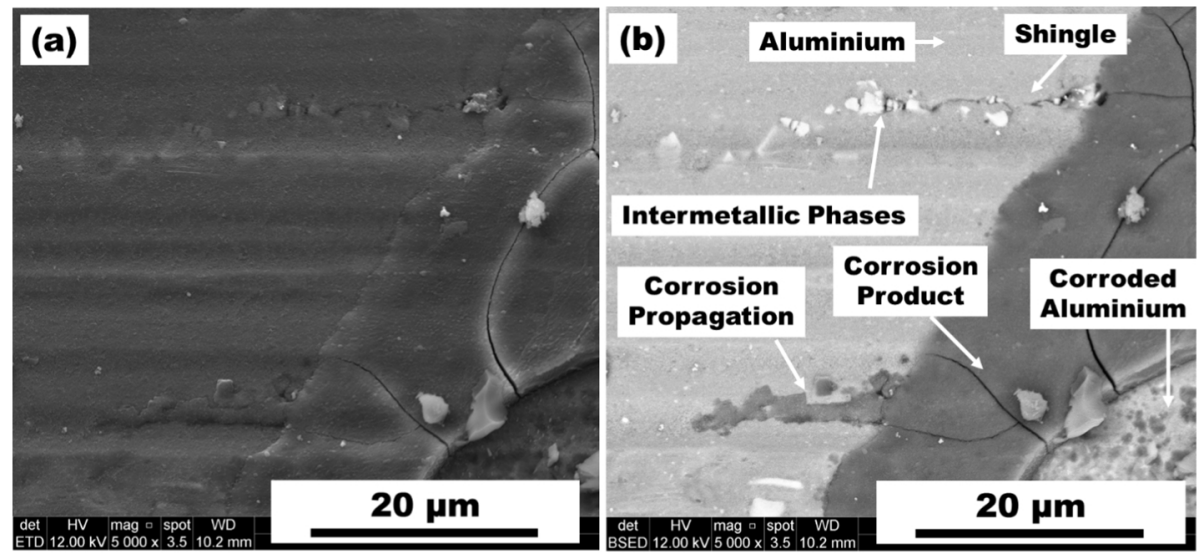

Figure 7 


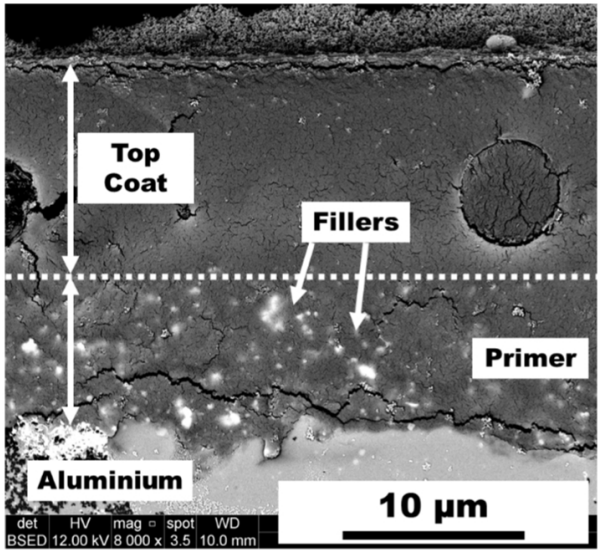

Figure 8 


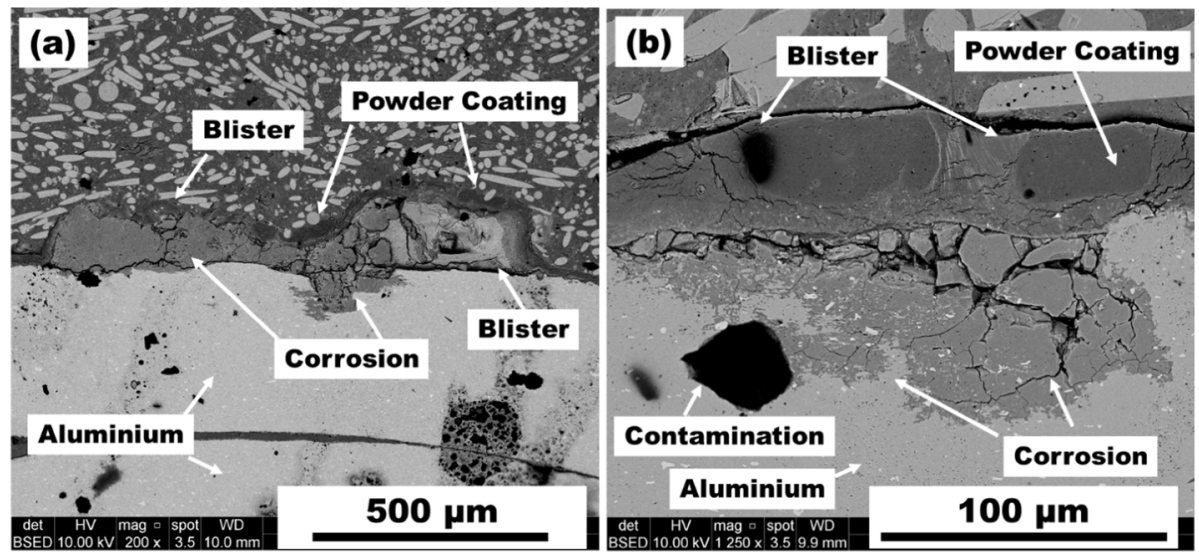

Figure 9 


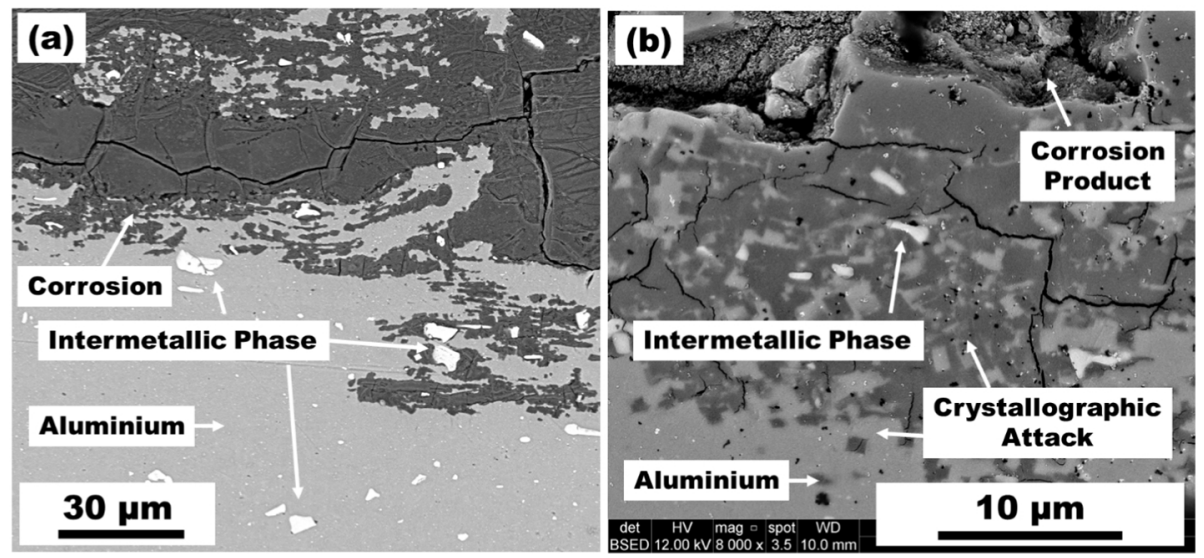

Figure 10 


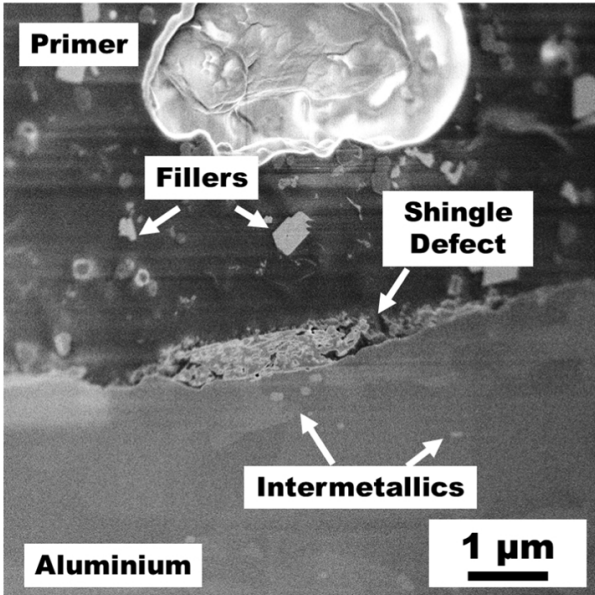

Figure 11 


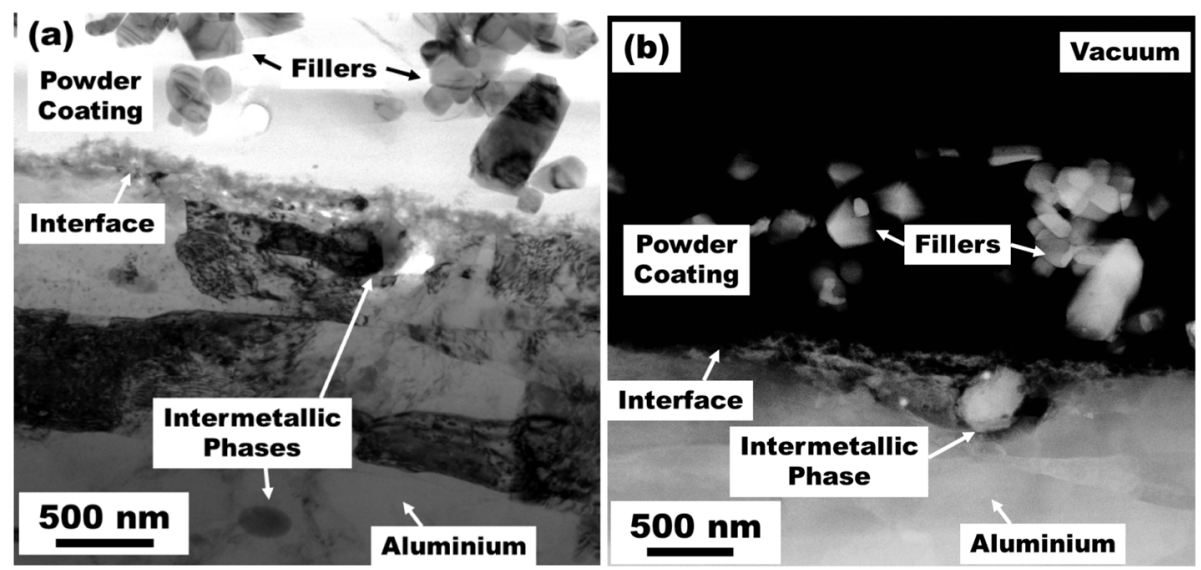

Figure 12 


\section{1 $\mathrm{mm}$}

Vacuum
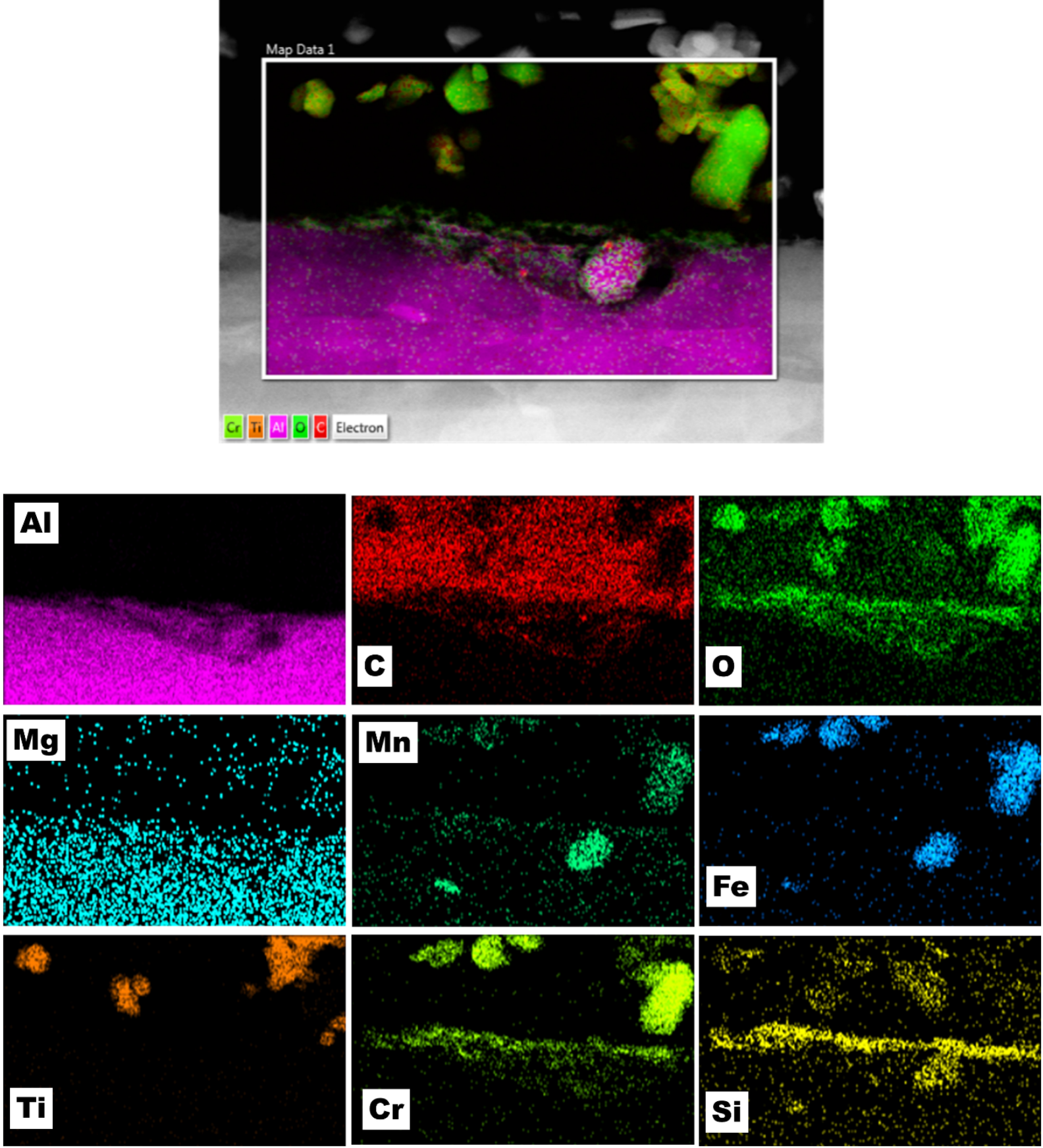

Figure 13 


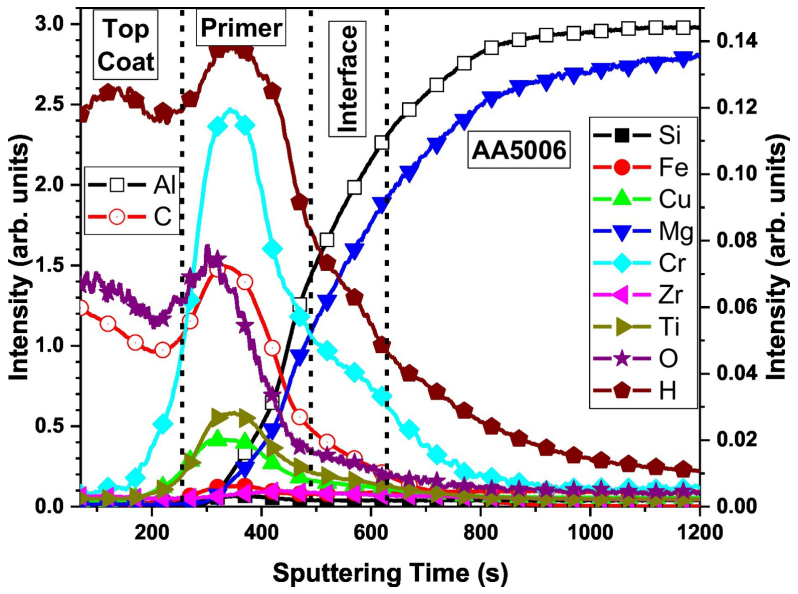

Figure 14 


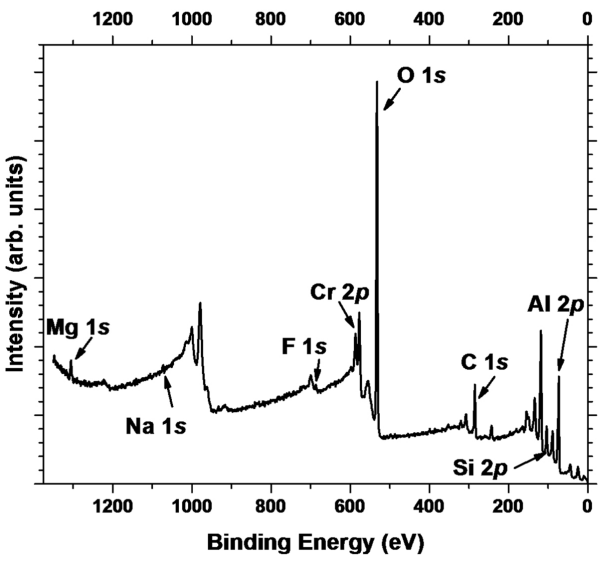

Figure 15 
